\title{
Towards infant formula biomimetic of human milk structure and digestive behaviour
}

\author{
Claire Bourlieu $^{1,2, *}$, Amélie Deglaire ${ }^{1}$, Samira Cassia de Oliveira ${ }^{1}$, Olivia Ménard ${ }^{1}$, Yann Le Gouar ${ }^{1}$, \\ Frédéric Carrière ${ }^{3}$ and Didier Dupont ${ }^{1}$ \\ ${ }^{1}$ INRA-Agrocampus Ouest, UMR 1253 STLO, Rennes, France \\ 2 INRA-CIRAD-SupAGRO-UM UMR IATE, Montpellier, France \\ ${ }^{3}$ CNRS-UMR 7282 EIPL, Marseille, France
}

Received 11 January 2017 - Accepted 6 March 2017

\begin{abstract}
Lipids of human milk or infant formula convey most of the energy necessary to support the newborn growth. Until recently, infant formula chemical composition had been optimized but not their structure. And yet, more and more proofs of evidence have shown that lipids structure in human milk modulates digestion kinetics and is involved in metabolic programming. Indeed there is a striking difference of structure between human milk which is an emulsion based on dispersed milk fat globules $(4 \mu \mathrm{m})$ secreted by the mammary gland and submicronic neoformed lipid droplets $(0.5 \mu \mathrm{m})$ found in infant formula. These droplets result from a series of operation units. This difference of structure modifies digestion kinetics and emulsion disintegration in the intestinal tract of the newborn. This difference persists along gastric phase which is mainly dominated by acid and enzyme-induced aggregation. Lipid droplets size is thus the key parameter to control gastric lipolysis and emptying and intestinal lipolysis. This parameter also controls proteolysis since adsorbed proteins are more rapidly hydrolyzed than when in solution. In animal models, these differences of lipid structure would also impact digestive and immune systems' maturation and microbiota. Lipid structure during neonatal period would also be involved in the early programming of adipose tissues and metabolism. The supplementation of infant formulas with bovine milk fractions (milk fat globule membrane extracts, triacylglycerol) or recent development of large droplets infant formula, along with new fields of innovation in neonatal nutrition, are here reviewed.
\end{abstract}

Keywords: human milk fat globules / lipid structure / infant formula / neonatal digestion / programming

Résumé - Vers des formules infantiles mimant la structure et le profil de digestion du lait maternel. Les lipides laitiers du lait maternel ou de formules infantiles fournissent la plupart de l'énergie disponible pour la croissance du nouveau-né. Jusqu'alors, la composition chimique des formules infantiles a été optimisée mais pas leur structure. Or il est de plus en plus démontré que la structure des lipides dans le lait maternel module les cinétiques de digestion et participe à la pré-programmation métabolique. Il existe en effet une différence majeure entre les émulsions natives de globules gras laitiers $(4 \mu \mathrm{m})$ sécrétées par la glande mammaire et la structure des lipides dans les formules infantiles qui résultent d'une succession d'opérations unitaires de transformation et sont constituées de gouttelettes submicroniques $(0.5 \mu \mathrm{m})$ avec des interfaces néoformées. Cette différence de structure modifie les cinétiques de digestion et de déstructuration des émulsions dans le tractus digestif des nouveau-nés. De façon générale, la différence de structure initiale entre lait maternel et formules infantiles se maintient pendant toute la phase gastrique, qui est surtout dominée par des mécanismes d'agrégation acide et enzymatique. La taille des gouttelettes est le paramètre clé pour contrôler les lipolyses gastrique et intestinale et module également la vitesse de vidange gastrique néonatale. Ce paramètre contrôle également les cinétiques de protéolyse puisque les protéines adsorbées sont hydrolysées plus rapidement que les protéines solubilisées. Ces différences de structure impacteraient également chez l'animal le développement des systèmes digestif, immunitaire et la mise en place du microbiote. La structure des lipides ingérés pendant la période néonatale pourrait également

\footnotetext{
* Correspondence: claire. bourlieu-lacanal@inra.fr
} 
participer à la pré-programmation des tissus adipeux et du métabolisme chez l'adulte. La réintroduction d'extraits membranaires et de triacylglycérols issus de lait bovin dans les formules, le développement de formules nouvelles basées sur des émulsions moins fines ainsi que les dernières tendances de développement de formules infantiles biomimétiques sont reportées et discutées dans cette synthèse.

Mots clés : globules gras / lait maternel / structure lipidique / formules infantiles / digestion néonatale

\section{Introduction}

Human milk (HM) chemical composition was established for the first time in 1838 (Cone, 1981). Since then, this chemical composition has been the basis for preparing infant formula (IF). However, proofs of evidence of the part played by HM structure in the concept of early programming have been produced over the last decade (Oosting et al., 2011). These new findings have refocussed a large part of innovations in targeting IF than are biomimetic of HM in terms of structure but also in terms of digestive behaviour.

Diet in the early life modulates not only short-term outcomes such as growth, but also long-term health outcomes along life (Victora et al., 2016). Factors which are potentially influenced by diet during neonatal period, include neurodevelopment, metabolic health, immune competency, atopic disease, establishment of the mucosal microbiome and behavioural responses to foods and eating (Maslowski and Mackay, 2011; Arrieta et al., 2014; Raiten et al., 2016).

Despite the great advances in the optimization of IF composition, IF cannot provide all the numerous immune protective and bioactive factors present in HM. In addition, IF lipids structure has remained up to now very different from $\mathrm{HM}$, which can lead to a difference in the kinetics of digestion and assimilation of nutrients (Armand et al., 1996; Bourlieu and Michalski, 2015; Bourlieu et al., 2015a). Indeed lipids in $\mathrm{HM}$ are found under the form of dispersed droplets called Milk Fat Globules (MFG, Ø $0.1-20 \mu \mathrm{m}$, average $=4 \mu \mathrm{m})$. This native $\mathrm{MFG}$ is a unique biophysical element differing from other lipoproteic objects (lipoproteins, oleosomes, etc.) by its external trilayered membrane inherited from its secretion by the lactocyte. The MFG membrane (MFGM) is tensioactive and consists in potentially bioactive polar lipids (glycerophospholipids, sphingolipids and glycosphingolipids such as gangliosides), cholesterol, proteins, glycoproteins, enzymes and minor components such as RNA/miRNA (Lopez and Ménard, 2011; Bourlieu and Michalski, 2015; Lopez et al., 2015). Due to its heterogeneous chemical composition, this membrane presents a specific physical-state, with phase coexistence: nanodomains called lipid rafts (i.e. sphingolipids and cholesterol that aggregate along sections of the membrane) are in the lipid-ordered phase and are characterized by a high degree of rigidity; besides, other parts of the MFGM concentrating more unsaturated molecules are in liquiddisordered state (Gallier et al., 2010; Lopez and Ménard, 2011). On the contrary, the IF emulsion is based on several reassembled dairy and non-dairy fractions, resulting from successive technological operations. IF lipids are generally composed of submicronic droplets $(0.3-0.8 \mu \mathrm{m})$ stabilized by a neoformed membrane mainly based on milk proteins and non-dairy tensioactive molecules.

Since HM is a complex and dynamic fluid very difficult to mimic, most improvements of IF have consisted in the addition of components individually identified as bioactive in HM, in the optimized IF (Committee on the evaluation of the addition of ingredients new to infant formula, 2004; Gallier et al., 2015; Zou et al., 2016). Notably, components such as long chain polyunsaturated fatty acids (LCPUFA), lactoferrin, nucleotides, essential amino-acids (AA), oligosaccharides (OS), prebiotics, probiotics can be added into some IF.

The interest for HM lipid structure started in the 70s with studies showing specific triacylglycerol (TG) structure in $\mathrm{HM}$ and resulting improved fatty acids absorption (Tomarelli et al., 1968). Understanding the higher levels of organization of human MFGM or MFG has been delayed until the development of modern biophysical tools (among which confocal laser scanning microscopy). And yet, despite these developments and the obvious nutritional importance of HM, data on HM lipid structure remains limited (Simonin et al., 1984; Michalski et al., 2005b; Zou et al., 2012; de Oliveira et al., 2015, 2016, 2017). Many structural characteristics of HM MFG have been inferred from cow's MFG which paradoxically has been more studied.

Over the last decade, going beyond HM individual lipids has been the new priority. Understanding human MFG's fate and behaviour in the gastro-intestinal tract, and the part MFG play in intestinal, immune and metabolic programing has become central question in neonatal nutrition. How milk emulsion droplets interact with each other and respond to different environmental conditions depends on the emulsion properties (i.e. size of MFG and quantity of interface, type and organization of proteins) and on the characteristics of the interfacial layers (i.e. thickness, composition, charge) (Singh et al., 2009; Bourlieu and Michalski, 2015; Gallier et al., 2016). These characteristics differ among milks (e.g. HM and bovine milk) and are modified after milk technological treatments (heat treatments, homogenization) (Innis et al., 2010; Gallier et al., 2012, 2013a, 2013b; Garcia et al., 2014; Bourlieu et al., 2015b; Le Huërou-Luron et al., 2016). Designing IF that mimic HM digestive behaviour supposes prior characterization of this behaviour. Recent work proposed by (de Oliveira et al., 2015, 2016, 2017) have described HM structural change during its passage through the upper gastrointestinal tract.

In this context, the objectives of the present reviews is to highlight recent findings about HM lipid structure, its evolution during digestion and putative part in nutritional programming which have opened the way to recent innovations in IF processing.

\section{Proofs of evidence of perinatal lipid nutrition and HM's structure being involved in programming and consequences for neonatal nutrition}

At birth, the gastrointestinal tract is immature and its development continues during the first year of life. Although genetically programmed, the infant's intestinal and immune 
development is modulated by the diet (Le Huërou-Luron et al., 2010). The critical part played by essentials FA (linoleic acid LA and alpha-linolenic acid ALA) and LCPUFA (especially docosahexaenoic acid DHA and arachidonic acid ARA) during neonatal period in brain growth, cognitive skills development, motor and retinal functions were established early (Yehuda et al., 2005). Infant brain growth and associated DHA accumulation is significant during the last trimester of gestation and continues during early infancy (Lapillonne, 2007). And yet, the capacity of bioconversion of LA and ALA to LCPUFA is limited during neonatal period inducing a dependence on the dietary intakes from HM or IF lipids. The impact of lipids on the early programming of intestinal functions and metabolism was questioned later than for carbohydrates or proteins. Early works of Ailhaud and collaborators established that among LCPUFA, ARA was a precursor of prostacyclin in preadipocytes and was very adipogenic in vitro (Gaillard et al., 1989). Contribution of ARA to adipose tissue development during perinatal period was further investigated in rodents. This investigation allowed demonstrating that mother's diet with variable LA/ LNA ratios (LA being ARA precursor) impacted pup's body composition (fat mass, adipocytes size, etc.) (Massiera et al., 2003). Since gestation and first year of life are the most important windows of adipose tissue proliferation, they set the hypothesis that this difference in body composition persisted later in life. These observations showed that ARA via metabolism of LA was a key determinant in fat mass and globally underlined that LA/LNA ratios during perinatal period could have important programming effect on body composition (Ailhaud et al., 2006). Further proofs of evidence of lipids being involved in programming other functions were obtained in 2010 in animal models (rodents) by two research groups (Innis et al., 2010; Oosting et al., 2010). These results were obtained on non-dairy lipids but paved the way for further investigations on 'dairy lipid structure and programming' conducted just after by Oosting et al. $(2011,2012,2014)$.

\subsection{The $n-6 / n-3$ ratio in key factor of perinatal nutrition and programming}

Innis et al. (2010) proposed that the increasing incidence of inflammatory bowel disease observed in Western countries over the last decades could be linked to dietary factors including perinatal lipid nutrition. They set the hypothesis that perinatal lipid nutrition affects, directly or indirectly through microbiota modulation, the epithelial barrier function and development, immune system and inflammatory response. Thus perinatal lipid nutrition could alter early intestinal development and programs future response to inflammatory diseases in adulthood in animal model (rats). In their study, perinatal supply of $n-6$ and $n-3$ polyunsaturated FA was modified through the mother's diet. Diets was administrated throughout gestation and lactation and contained as \% energy either $20 \%$ safflower oil (SO), $20 \%$ canola oil (CO), or $8 \%$ fish oil (FO) plus $2 \%$ SO (10\% FO), or $18 \%$ FO plus $2 \%$ SO $(20 \%$ FO). At 15 days of age, pups in the $20 \%$ and $10 \%$ FO groups had lower ARA (20:4 n-6) and higher eicosapentaenoic acid (20:5 $n-3)$ and DHA (22:6n-3) in colon phospholipids $(P<0.01)$, shorter intestinal crypts $(P<0.05)$, and higher paracellular permeability than in $\mathrm{SO}$ or $\mathrm{CO}$ groups. Later on, after weaning to standard diet (21 days) and at a stage representing adulthood (i.e. 3 months of age) male offspring in the FO groups showed homogeneous colon phospholipid FA composition but lasting reduction of crypt depth and an enhanced inflammatory response when challenged with dinitrobenzene sulfonic acid (chemically-induced colitis). The eicosanoid metabolite prostaglandin E2 (PGE2) synthesized via cyclooxygenase $\mathrm{COX}-1$ and COX-2 from ARA and influencing intestinal cell crypt survival, proliferation and permeability was proposed as putative mechanisms for this programming effect.

At the same time, Oosting et al. (2010) investigating further Ailhaud's group hypothesis (Ailhaud et al., 2006), established still in a rodent model, that $n$-3 LCPUFA-rich neonatal diet programmed adult body composition (reduction of $30 \%$ fat accumulation during western style diet challenge) and metabolic homeostasis. Healthier plasma lipid profile, plasma glucose parameters and less adipocytes hypertrophy were observed in the group of mice that had received the $n-3$ enriched diet during neonatal period. Oosting et al. (2010) set the hypothesis that unbalanced $n-6 / n-3$ neonatal intake favoured LA conversion to ARA and its eicosanoids metabolites. These metabolites may directly stimulate adipogenesis through activation of peroxisome proliferator-activated receptor delta and gamma.

Breastfeeding is associated with specific growth pattern compared to classic IF feeding, this pattern is marked by moderate early growth and lower fat mass (Nommsen-Rivers and Dewey, 2009). Several meta-analyses have shown that breast-feeding has a small protective effect against obesity later in life (Agostoni et al., 2009). Relying on these positive outcomes and considering the strong difference of lipid structure between IF and HM, Oosting et al. (2014) set the hypothesis that HM lipid structure was involved in programming.

\subsection{Difference in lipid structure between human milk and classic infant formula and its potential influence on programming}

Human milk is an emulsion of lipid in water and lipids are organized under the form of MFG stabilized by a trilayered membrane (Fig. 1). This membrane is mainly composed of polar lipids (phospholipids and glycosphingolipids) but also of apolar lipid such as cholesterol. MFG structure has been presented as a key element for HM lipid paradoxical metabolic fate: MFG is a rapid conveyor of energy through its triacylglycerol (TG) core but contains some low-digestible bioactive complex lipids and proteins which influence lipid metabolism and contribute to intestinal and systemic health. On the contrary IF formula are generally based on a blend of vegetable lipids and found under the form of submicronic droplets stabilized by dairy proteins or non-dairy tensioactive (vegetable lecithins, functionalized lecithins or esters of partial glycerides mainly) (Fig. 2). Taken individually, milk polar lipids present in MFGM have proven bioactivities, with reported impact on cell metabolism, on brain development and cognitive functions, and on immunity and gut health (Hirabayashi and Furuya, 2008; Kullenberg et al., 2012; Lonnerdal, 2014). Some benefits of the MFGM have been 

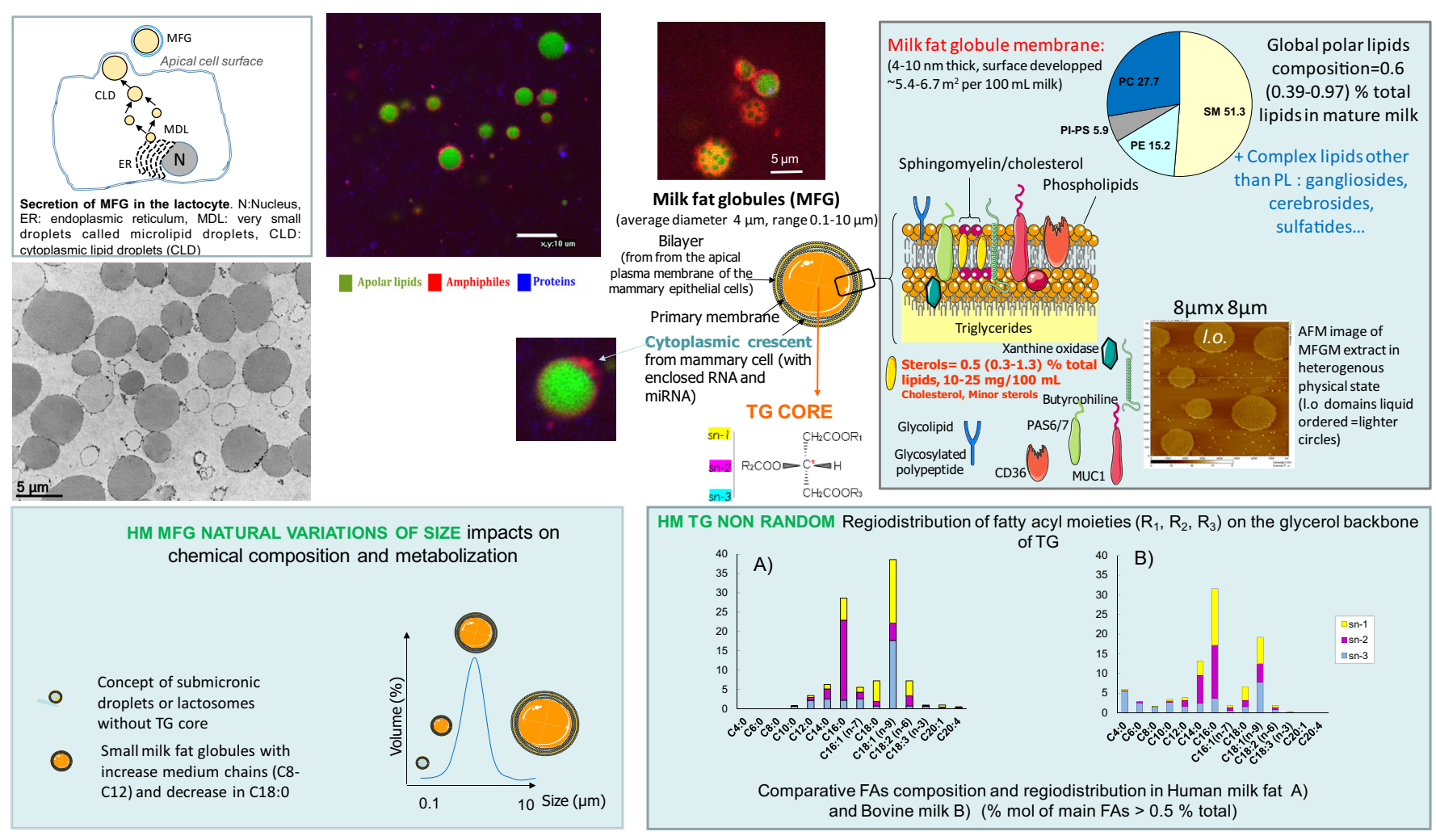

Fig. 1. Origin and structure of lipids in human milk. Adapted with modifications from Bourlieu and Michalski (2015) and Bourlieu et al. (2015a).

associated specifically to the combination of its components and their structural organization (Bourlieu and Michalski, 2015). MFG membrane configuration is reported to protect some bioactive molecules and retard their digestive breakdown, allowing them to exert their function until the distal intestinal part. For instance, the limited susceptibility of sphingomyelin to digestion favours the persistence of sphingomyelin-cholesterol complexes in the proximal part of the intestine. In addition, sphingomyelin and its metabolites (ceramide, sphingosine, ceramide-1-P and sphingosine-1-P) influence TG hydrolysis, cholesterol absorption, lipoprotein formation and mucosal growth in the gut (Nilsson and Duan, 2006). It was also hypothesized that milk sphingolipids could play a protective effect against bacterial toxins and bacterial development via a competition for bacteria binding sites as many bacteria binds to epithelial cell via glycosphingolipids (El-Loly, 2011). Milk sphingolipids transiting in the gut may decrease pathogens adherence to the intestinal mucosa facilitating pathogens elimination (Sprong et al., 2001) and thus influence the gut microbiota composition. The bactericidal activity of digestion products of sphingolipids and more specifically of lysosphingomyelin was evidenced in vitro by Sprong et al. (2001). Along sphingolipids, glycosylated proteins and lipids that also escape upper intestinal digestion are also crucial factors contributing to MFGM bioactivity. Additionally, the protective structure of the MFG membrane contributes to the high oxidative stability of expressed HM, despite its high content in LCPUFAs (Michalski et al., 2008).

Considering the striking difference in size and interfacial composition between classic IF and HM, (Oosting et al., 2012) investigated, still in an animal model (mice), whether the administration of a concept 'more breastmilk like' formula compared to a standard formula could program adult body composition and metabolism. The concept IF Nuturis ${ }^{\circledR}$ (WO2013135739A1) is based on large vegetable fat droplets (mode, i.e. most frequent size in the distribution in volume, of $6.25 \mu \mathrm{m})$ covered by milk phospholipids $(2 \mathrm{~g} / \mathrm{L})$. Thus the particle size distribution, emulsion interfacial composition and organization is very close, although not totally similar, to $\mathrm{HM}$ (Gallier et al., 2015). The administration during the neonatal period (from day 16 to 42 ) of this Nuturis ${ }^{\circledR}$ formula in mice, followed by a western diet challenge, resulted during adulthood to lower fat accumulation, lower fasting plasma leptin, resistin, glucose and lipid (TG and total cholesterol) than in the group fed conventional formula (Oosting et al., 2012). The mechanisms underlying this nutritional programming effects of Nuturis ${ }^{\circledR}$ remained at this stage unclear and very likely plurifactorial. However, authors hypothesized that emulsion droplets size and interface could modify digestion kinetics. At this stage, limited and quite conflicting results had been published on milk emulsion digestion (Armand et al., 1996, 1999) suggesting that adult would digest faster small droplets based emulsion which would not be the case for infants. Since then, these results have been fully clarified and will be summarized in Section 3. At this stage, however, the fact that kinetics of lipid digestion could further modulate plasma TG appearance (Michalski et al., 2006) and $\beta$-oxidation rate (Michalski et al., 2005a) was already established in animal models and later on confirmed in human (Vors et al., 2013). In a further study (Oosting et al., 2014), still using a very close design study in mice, it was shown 
INFANT FORMULA LIPID DROPLETS PROCESSING

\begin{tabular}{|c|c|}
\hline Ingredients & 1. Blending \\
\hline Liquid preparation & 2. Pasteurization \\
\hline \multirow{2}{*}{ concentrate } & 3. Vacuum concentration \\
\hline & 4. Homogenization \\
\hline \multirow{3}{*}{ powder } & 5. Spray-drying \\
\hline & 6. Blending during Spray-drying \\
\hline & 7. Blending after Spray-drying \\
\hline \multirow{2}{*}{ packaged powder } & 8. Big bag packaging \\
\hline & 9. Quality control \\
\hline & 10. Individual packaging \\
\hline
\end{tabular}

\section{PROCESS-INDUCED VARIATIONS OF SIZE AND STRUCTURE impacts} on digestion and metabolization

Submicronic droplets with neoformed membrane formed by homogenization/heat treatment
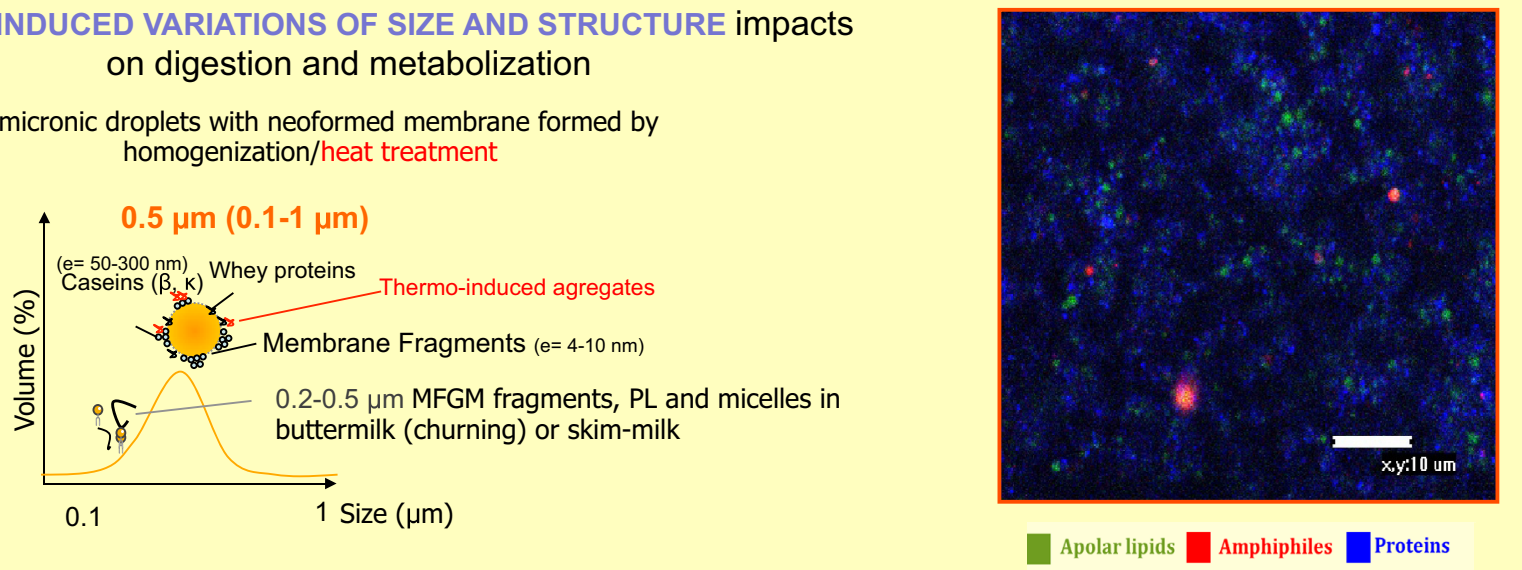

Fig. 2. Origin and structure of lipids in infant formulas. Adapted with modifications from Bourlieu and Michalski (2015) and Bourlieu et al. (2015a).

that neonatal administration of Nuturis ${ }^{\circledR}$ IF induced in adulthood, reduced adipocyte size without affecting their number in epididymal white adipose tissue. This was accompanied by the modulation of several transcription factors involved in metabolic regulation such as peroxisome proliferator-activated receptor gamma, CCAAT/enhancer-binding protein and retinoid $\mathrm{X}$ receptor.

The last recent study on the physical structure of lipids and its programming effect, aimed at evaluating whether the protective effect against obesity in adulthood was arising from the droplet size and/or from the droplet membrane (Baars et al., 2016). Only the administration of large droplets with phospholipid coating, i.e. the combination of the two factors under the Nuturis ${ }^{\circledR}$ formula form, during the neonatal period reduced fat accumulation in adulthood. A direct effect of MFGM contained in the concept formula, was also weakened by a recent study comparing the growth of infants fed with a standard IF vs. a formula enriched with MFGM fragments (Timby et al., 2014a). The study did not reveal any difference in infant growth, weight gain and body fat at 12 months. Conversely, HM lipids affected preadipocyte differentiation in vitro in the absence of the standard adipogenic compounds, which was not observed with IF lipids (Fujisawa et al., 2013).
Thus, among the structural aspects of HM lipids, both lipid droplet size as well as the MFGM coating, may contribute to its reported protective effect against obesity (Baars et al., 2016). Nuturis ${ }^{\circledR}$ IF is currently being testing in an interventional clinical trial in healthy term infants (NCT01609634) for its tolerance, safety and impact on growth and body composition up to 24 months.

\section{Approaches to develop biomimetic IF}

\subsection{Mimicking milk fat globule coverage}

Since the stability of large droplet-based emulsion like Nuturis ${ }^{\circledR}$ IF is a real technological challenge, another more straightforward strategy to produce more biomimetic IF has consisted in supplementing classic IF with bovine MFGM extract, without considering the lipid droplet size.

On a technological point of view, MFGM fractions are isolated from by-products of the butter industry, such as buttermilks and butterserums (El-Loly, 2011; Conway et al., 2014). These fractions can be concentrated thanks to the development of micro and ultrafiltration technologies (Morin et al., 2006, 2007a, 2007b; Gassi et al., 2016). These compounds 
appear as an attractive alternative to non-dairy tensioactive or milk proteins to better approach HM ultrastructure. These compounds can be added in the IF premix. An important aspect of such addition is not only their protein/phospholipids ratios but also the order of introduction of these two amphiphiles in the emulsion which can impact on the emulsion interfacial composition and structure (Bourlieu et al., 2015a; Gallier et al., 2015). The precise interfacial composition of such biomimetic IF remains to be characterized as well as its susceptibility to digestion.

In terms of clinical impact, six double-blinded randomized controlled Clinical trials in infants and children have investigated the safety and efficacy of such IF supplementation with bovine MFGM (Hernell et al., 2016). Results are mostly positive and demonstrate benefits in terms of cognition, behaviour, gut health and immunity (Zavaleta et al., 2011; Gurnida et al., 2012; Veereman-Wauters et al., 2012; Billeaud et al., 2014; Poppitt et al., 2014; Timby et al., 2014a, 2014b, 2015). Although the intervention strategy and MFGM concentrates added are still too heterogeneous, these results provide evidence of the beneficial effects of individual components of MFGM.

On the other hand, at a very different level, i.e. the molecular level, it is well known that interfacial composition of milk lipids influence digestive lipases activity. The way MFGM organization modulates digestive lipase activity is now well described. Considering first gastric lipase, (Bourlieu et al., 2016) established that its adsorption was favoured in more fluid like part of the MFGM, i.e. in liquid-disordered phase of the membrane where products of lipolysis, free fatty acids, concentrate. In addition, the presence of residual negative charges in the MFGM could also favour lipolysis kinetics. On the contrary gastric lipase would not adsorb onto liquid-ordered domains where sphingomyelin and cholesterol concentrate. Quite similar observation in intestinal phase has been reported for human pancreatic lipase which selectively adsorbed with colipase onto liquid disordered phase (Chu et al., 2010). The close packing of the hydrophilic lipid headgroups in liquid ordered domains prevented lipase adsorption by steric hindrance. These liquid ordered domains concentrating SM and cholesterol are thus supposed to be transported along the intestine, playing potential antimicrobial activities. Conversely, liquid disordered domains where free fatty acids concentrates constitutes evolving and preferential zone for pancreatic lipase, colipase and carboxylester lipase adsorption (Sugar et al., 2001, 2003). Considering this high effect of MFGM composition and organization on digestive lipase activity, the non-dairy tensioactives (vegetable lecithins, functionalized lecithins or esters of partial glycerides mainly) authorized in IF can be questioned. These non-dairy tensioactive are notably used in hydrolyzed IF where tensioactive dairy protein can not play their stabilizing part. Indeed the non-digestibility of some of these constituents, citric acid esters of mono- and diglycerides, was recently evidenced by Amara et al. (2014).

\subsection{Mimicking MFG core: the importance of TG regiodistribution}

The core of MFG is composed mainly of TG. These TG have a specific structure induced by the non-random regiodistribution of the FA on the glycerol backbone. This specific regiodistribution is a fairly constant feature of HM that does not evolve with lactation stage (Martin et al., 1993). Proofs of evidence of the nutritional importance of such regiodistribution have been demonstrated as soon as the $70 \mathrm{~s}$ (Tomarelli et al., 1968). This regiodistribution differs between bovine and HM (Fig. 1), but also more importantly between IF and HM, since the source of fat in IF is in most cases a combination of blended vegetable oils which mimics the FA composition of HM (Bourlieu et al., 2015a; Zou et al., 2016). Vegetable fats also show non-random regiodistribution but in the opposite way to dairy fat: their saturated FA are typically positioned on the external $s n-1,3$ positions, whereas unsaturated FA are mainly located in $s n-2$ position (Straarup et al., 2006; Innis, 2011). As a result, most commercial IF based on blends of vegetable fats present a TG structure that differs largely from the one of HM fat (Kurvinen et al., 2002). The regiodistribution of the FA on TG affects the FA lipolysis and its subsequent uptake (Bourlieu et al., 2009; Zou et al., 2012), as digestive lipases are also regio- or stereoselective. For instance, MCFA (C8:0 to C12:0) are mainly esterified in $s n-3$ position in HM, and thus selectively released by the $s n-3$ stereospecific human gastric lipase (HGL). These medium chain FA are then absorbed via the portal vein, transported to the liver to be $\beta$-oxidized, and thus constitute a rapid source of energy for the newborn (Bourlieu et al., 2015a). Oleic acid (C18:1 n-9) is usually found at the $s n-1$ and $s n-3$ positions, which corresponds to the stereo-specificity of the human pancreatic lipase. Palmitic acid (C16:0) mostly present at the $s n-2$ position favours its intestinal absorption as $s n-2$ monoglyceride (Jensen et al., 1978; Bernback et al., 1990; Bourlieu and Michalski, 2015) and limits loss of calcium/ palmitate salts in stools.

In order to get closer to the structure of the $\mathrm{TG}$ found in HM, fat analogs $\left(\right.$ Betapol $^{\circledR}$ and INFAT $^{\circledR}$ ) are commercially available; these analogs are obtained after enzymatic or chemical modifications and aimed to mimick the FA regiodistribution found in HM. Notably, a special attention is paid to the positional distribution of palmitic acid, which presents substantial benefits for the infant growth when esterified at the $s n-2$ position, as in HM(Innis, 2011; Zou et al., 2016). However, these analogues are still not found in commercial IF (Straarup et al., 2006) probably due to their cost but also to the reject of health claim petitions for beta-palmitate (increase in calcium absorption and softening of stool) by the European food Safety authority in 2011 and 2014 (Zou et al., 2016).

The reintroduction of bovine milk fat which share close TG regiodistribution with HM up to $50 \%$ total fat in IF has been advocated by various research groups (Bourlieu et al., 2015a; Delplanque et al., 2015; Hernell et al., 2016; Lonnerdal, 2016). In addition dairy fat enriched with ALA was proven superior to plant oil blend for DHA brain restoration in animal model (Delplanque et al., 2011, 2013). ALA deficient rat pups fed by a palm-oil-blend-based diet $(0.4 \%$ ALA) over gestation and lactation were, at weaning, fed either a palm-oil-blend-based diet or dairy fat supplemented with sunflower and rapeseed oils. Both diets contained recommended amounts of ALA i.e. $1.5 \%, 14-16 \%$ LA and LA/ALA ratio $\sim 9-10$. The dairy fat diet induced more DHA accumulation than the vegetable oil based diet. Supplementation of the vegetable-oil-based diet with DHA (0.12) and ARA (0.4) to mimic LCFA enriched IF did not modify this trend. No modulation of desaturase or elongase activity was detected in the various diets. Authors 
thus set the hypothesis that short chain FA contained in dairy fat which are good substrate for $\beta$-oxydation could prevent ALA from $\beta$-oxydation. ALA partitioning towards elongation and desaturation pathways would thus be favoured.

\subsection{Mimicking milk fat globule coverage and core}

Le Huërou-Luron et al. (2014) hypothesized and checked in animal model (piglets) that IF with milk fats stabilized by MFGM closer to HM would impact differently neonatal digestive physiology and microbiota. The presence of milk lipids in IF led to a higher resistance to digestion of dairy proteins (casein and $\beta$-lactoglobulin) as compared to formula with vegetable lipids. This effect can be due to differences in the emulsion interface composition between the two formulas, with more dairy proteins adsorbed in the vegetable fat based IF devoid of MFGM; indeed both lactoglobulin and caseins are more susceptible to proteolysis when adsorbed to an oilwater interface than in solution (Macierzanka et al., 2009). The developmental profile of intestinal immune cells was also modulated by the lipid composition of formula. Proinflammatory cytokine secretion of mesenteric lymph node cells was enhanced in milk fat formula-fed piglets compared to vegetable fat fed ones. Overall, the addition of milk fat to IF led to the maturation of the immune system of milk fat fed piglets was closer to the one of mother-fed piglets. Finally, fat source also impacted the microbiota: Piglets fed the formula with a blend of vegetable fat and milk lipids had a higher percentage of fecal Proteobacteria and Bacteroidetes and lower Firmicutes than piglets fed the vegetable fat formula. The incorporation of both milk fat and MFGM fragments in IF by modifying gut digestion, its dynamic of immune maturation and faecal microbiota composition, changes formula immune functionality (Le Huërou-Luron et al., 2016).

Addition of dairy fat and MFGM also induced the addition of sterol enclosed in the MFG core. Sterols range from 10 to $25 \mathrm{mg} / 100 \mathrm{ml}$. Cholesterol stands for around $90 \%$ of sterol and globally declines in \% of total fat as lactation progresses (Jensen, 1999; Michalski, 2013). It was suspected very early that milk fat cholesterol ingested during neonatal period and before total maturation of hepatobiliary system contributed to cholesterol homeostasis in the adult (Reiser et al., 1979). It was demonstrated later on, that the high cholesterol content in HM leads to transiently higher total serum cholesterol concentration in infancy. However, later on in adulthood, the grown-up breastfed infants have lower total serum cholesterol concentration in comparison with a formula-fed group (Owen et al., 2002). More recently, Timby et al. (2014b) showed in a double-blinded randomized trial that increasing cholesterol intake between 2 and 6 months of age via bovine MFGM addition in IF induced an higher total serum cholesterol concentration similar to the one observed in breast-fed infants without modification of the LDL:HDL ratio.

\section{Data collected on human milk digestive behaviour in vitro and in vivo}

In the forefront of these systemic and long-term health effects of HM, characterizing its behaviour in the upper digestive part seems a priority to formulate IF having close digestive behaviour and properties. In vitro studies about HM and IF have contributed to clarify some points about the influence of the quantity and quality of the dairy emulsion interface on the digestion process (Bourlieu and Michalski, 2015; Gallier et al., 2016).

\subsection{Static or semi-dynamic neonatal model of digestion}

Though several pertinent static in vitro digestion models mimicking the infant digestive conditions have been proposed (Dupont et al., 2010; Bouzerzour et al., 2012; Bourlieu et al., 2014; Levi et al., in press), very few studies have investigated the behaviour of HM during static in vitro digestion. Most digestion models were employed to evaluate IF digestion (Lueamsaisuk et al., 2014). Chatterton et al. (2004), compared the protein breakdown of HM, whey protein concentrate and IF during in vitro gastric digestion using gastric juice of neonate. Gastric $\mathrm{pH}$ modulated strongly gastric proteolysis. Several HM proteins, including osteopontin and mucin present in the MFGM, resisted to digestion at $\mathrm{pH} 4$ and above. The resistance of some proteins of the MFGM to gastric proteolysis is a central element to explain the persistence of human MFG throughout gastric digestion. Globally protein from human or whey protein concentrate from bovine milk had a comparable behaviour during gastric digestion, conversely IF's protein which undergo several heat-treatment during IF processing, were more susceptible to proteolysis.

No static or semi-dynamic digestion model was applied to $\mathrm{HM}$ allowing characterizing $\mathrm{MFG}$ digestive behaviour. However, a semi-dynamic model was applied to concept IF containing either bovine MFG (mode $\sim 6 \mu \mathrm{m}$ ), or submicronic droplets resulting from high pressure homogenization alone or combined with post-homogenization heat-treatment (bimodal distribution with mods $\sim 0.2-0.6 \mu \mathrm{m}$ ) (Bourlieu et al., 2015b). This study established that the quantity of interface developed by milk lipids, directly influence gastric lipolysis and proteolysis kinetics. For milk emulsion having the same composition, initial rate of lipolysis was strictly proportional to the quantity of interface developed. Caseins $\left(\alpha_{\mathrm{s} 1}-\alpha_{\mathrm{s} 2}, \beta\right.$ and $\left.\kappa\right)$ were hydrolyzed faster than whey proteins $(\beta$-lactoglobulin and $\alpha$-lactalbumin) whatever the type of emulsion. However, caseins were even faster proteolyzed in homogenized emulsions compared to the emulsion based on minimally processed large bovine MFG. This enhanced susceptibility to proteolysis of casein when adsorbed at an hydrophobic interface had already been presented by (Macierzanka et al., 2009). The kinetics of gastric aggregation and internal structure of the aggregates were easily visualized on confocal scanning laser images. Magnifications and decompositions of the images (with or without protein labelling) revealed the persistence of preserved MFG or submicronic neoformed droplets. These lipid particles were the core elements around which protein aggregates built up.

\subsection{Dynamic models}

Zhang et al. (2014) investigated HM protein digestion using the Dynamic Gastric Model (DGM) to mimic the gastric conditions of infants aged of 9 to 12 months. Focusing on the 
MFGM proteins, this study highlighted that among the numerous proteins detected in HM, proteins such as lipoproteins or mucins RNASE linked to the MFGM were more resistant to gastric proteolysis and could exert complementary bioactivity similarly to intestinal mucin. The lower susceptibility to pepsin of the MGFM's proteins was explained by their glycolysation or the presence of disulphide bounds.

Fondaco et al. (2015) compared the behaviour of different IF and HM during dynamic gastro-intestinal digestion using the TIM-1 model (TNO, Zeist, The Netherlands). HM and IF were characterized by very different initial structure notably in terms of particles size distribution with main modes of $7 \mu \mathrm{m}$ in HM compared to $\sim 0.4 \mu \mathrm{m}$ in IFs. HM developed less viscosity than IF over the range of $\mathrm{pH}$ encountered during neonatal gastric phase ( $\mathrm{pH} 6$ to 4 mainly). Whether this limited viscosity could impact on gastric emptying and satiety was questioned by the authors. Bio-accessible FFA released in jejunum and ileum data were quantified. An initial rapid release of FFA was observed in each compartment for IF whereas a significant lag ( $\sim 90 \mathrm{~min}$ ) was observed for HM. In addition, a correlation between the rate of lipolysis and specific surface developed by IF which directly influence digestive lipase access. However, at comparable specific surface, HM presented higher lipolysis rate. Altogether, these result suggested that the structure of HM lipid impacts strongly its kinetics of digestion and that the rate of lipolysis is not dictated by specific surface alone but that other factor such as endogenous maternal BSSL and the unique interfacial properties of the MFGM could contribute after an initial LAG to boost lipolysis. These results are in agreement with previous result of (Armand et al., 1996) showing reduced lipolysis in the gastric aspirate of preterm after administration of IF compared to HM.

de Oliveira et al. $(2015,2016)$ used an in vitro dynamic system $\left(\right.$ DIDGI $\left.^{\circledR}\right)$ to study the gastrointestinal digestion of pooled mature HM $(n=5)$ either raw (RHM) or pasteurized (PHM). The digestive behaviour of HM was characterized using either term and preterm infant digestive conditions. Gastric digestion was marked by a strong emulsion destabilization, due to acid and enzymatic-induced aggregation. The pasteurization of HM reduced its gastric destabilization: whereas an important destabilization was observed in RHM, PHM particle size profile remained quasi-steady during all the gastric phase. Gastric aggregates formed during RHM digestion presented slightly larger modes in the preterm (mode $1=96.3$, mode $2=5.4$ at $30 \mathrm{~min}$ ) than in the term (mode $1=76.5 \mu \mathrm{m}$, mode $2=6.5 \mu \mathrm{m}$ at $60 \mathrm{~min}$ ) conditions. As observed by confocal laser scanning imaging, these aggregates were based on clusters of milk fat globules around which protein aggregates built up (Gallier et al., 2013a; Bourlieu et al., 2015b). Presenting lower density than milk aqueous phase, these lipoproteic clusters were prone to creaming in the gastric compartment. Such gastric destabilization in the adult favors a rapid gastric emptying of the aqueous low caloric watery phase, whereas the creamy phase is emptied more slowly (Golding and Wooster, 2010). The early gastric destabilization of raw HM observed here could be a protective mechanism favoring emptying and compensating the immature gastric motility in preterm newborns. Despite inactivation of endogenous lipase BSSL by pasteurization (activity levels of $23.4 \pm 3.3 \mathrm{U} / \mathrm{ml}$ in RHM and $0 \mathrm{U} / \mathrm{ml}$ in PHM as assessed by $\mathrm{pH}$-stat and using tributyrin as substrate), similar gastric hydrolysis rate and quasi similar hydrolysis degree were observed in RHM or PHM. Final gastric hydrolysis degrees ranged between $13.1 \pm 1.4 \%$ in preterm model to $24.1 \pm 3.2$ in full-term model. In addition, MFG were observed until at the end of gastric phase and delivered as preserved structure in the duodenum, which corresponds to a very specific delivery system of lipids unique to HM. With regards to the specificity of released FA short to medium-chains FA (C8:0 to C14:0) and LA were more released from RHM in the gastric phase, and are positioned mainly in the external positions $(s n-1,3)$ of the glycerol backbone (Innis, 2011; Bourlieu and Michalski, 2015). Such positions correspond to the regioselectivity of the gastric lipase ( $s n-3)$ and of the BSSL (mainly $s n-1$ and $s n-3$ ), which suggest a concerted action of gastric lipase and BSSL in the RHM (Bernback et al., 1990). When comparing the released FA with the acyl chains initially esterified in HM, it appeared that oleic acid (C18:1 n-9) and stearic acid (C18:0) were selectively released, as their relative amount were higher than that in the total esterified FA profile. In both gastric and intestinal digestion, C8:0 presented the higher percentage of release.

\subsection{Data collected on HM digestion in vivo in gastric compartment}

In an in vivo study on the preterm newborn, Armand et al. (1996) reported higher gastric lipolysis levels in HM compared with IF (which is homogenized), with values around $\sim 17 \%$ and $9 \%$ at $30 \mathrm{~min}$, respectively. These results suggested a lower accessibility of HGL to the TG core in the droplet of IF compared to HM, which was justified by the differences on the quality of the interface. Observations by transmission electron microscopy of gastric aspirates also allowed observing persistence of lipid structure in gastric phase. The quality of FFA released in gastric aspirate was not characterized.

Roman et al. (2007) analyzed products of lipolysis and human gastric lipase intragastric levels in preterm infants $(n=9, \mathrm{GA}=29+1 \mathrm{wk}, \mathrm{BW}=1.5 \mathrm{~kg}$, medium age $=34.3 \pm 1.8)$ fed either HM or medium chain-enriched IF. Medium chainenriched IF contained $20-40 \%$ (wt/wt) medium chain whereas HM contain only around $10 \%$. These medium chain FA are supposed to be better absorbed by the newborn as they can be directly absorbed through the gastric mucosa and transported via the portal vein and in intestinal phase their adsorption is less limited by biliary salt concentration compared to long chain FA. They observed similar rates of lipolysis for the IF and $\mathrm{HM}$ with lipolysis level reaching a maximum of $18 \pm 4 \%$ after $180 \mathrm{~min}$. The FFA and partial glycerides present in infant stomach during the 90-180 min time period were characterized. FFA profile was dominated in IF or HM group by palmitic acid $(17.0 \pm 0.2$ vs. $24.8 \pm 6.2 \%$ (wt/wt) in IF and HM respectively) and oleic acid (28.2 \pm 1.2 vs. $27.1 \pm 3.3 \%$ (wt/ wt) in IF and HM respectively). Released caprylic acid (C8:0) was not much higher in the enriched IF $(5.5 \pm 1.2$ vs. $3.5 \pm 1.5 \%$ (wt/wt) in IF and HM respectively) and analysis of partial glycerides confirmed this trend. This limited release can probably be explained by the limited amount of caprylic acid present in $s n-3$ position in vegetable fat compared to dairy fat.

de Oliveira et al. (2017) compared the gastric behaviour of pasteurized or raw $\mathrm{HM}$ in the preterm infant $(n=12$, 
A) Gastric structural evolution of HM
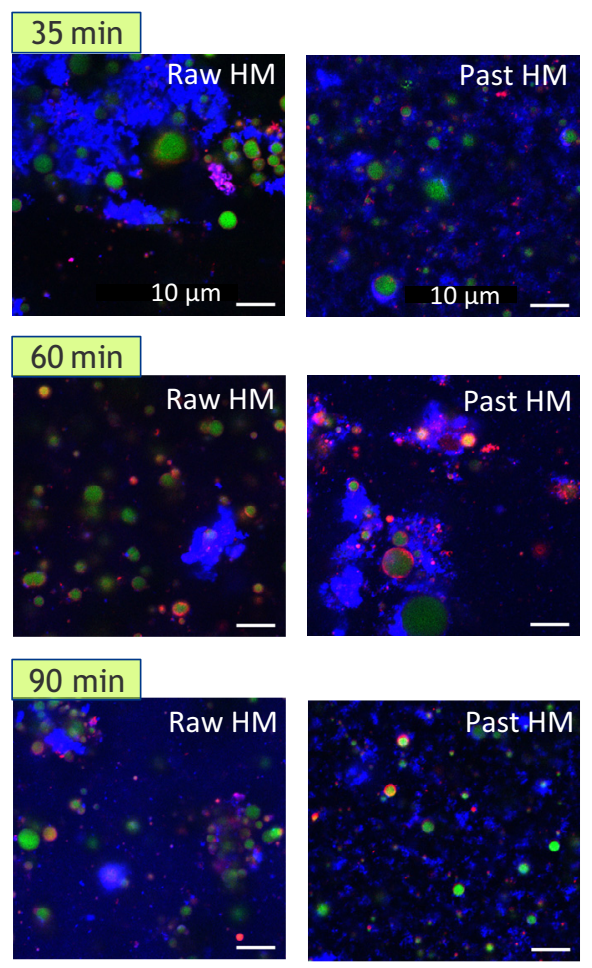

Apolar lipids
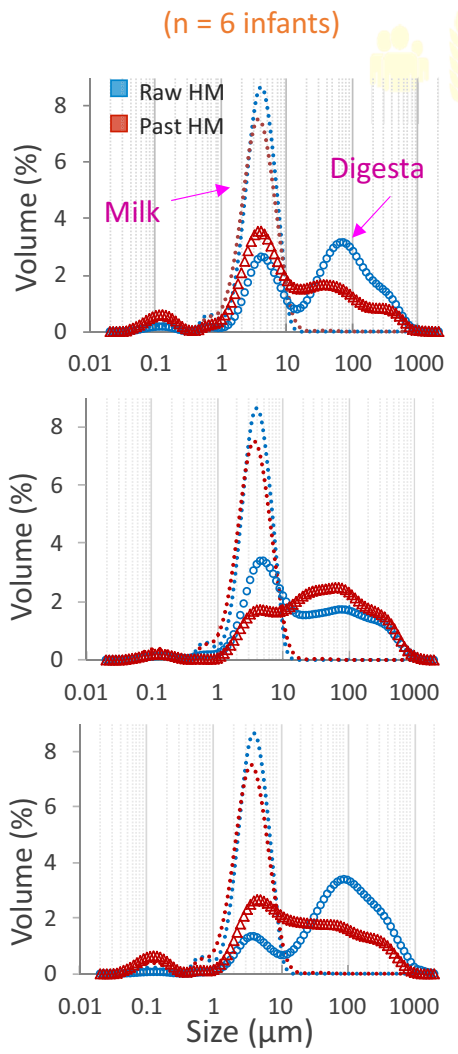

B) Instantaneous lipolysis and FA bioaccessibility

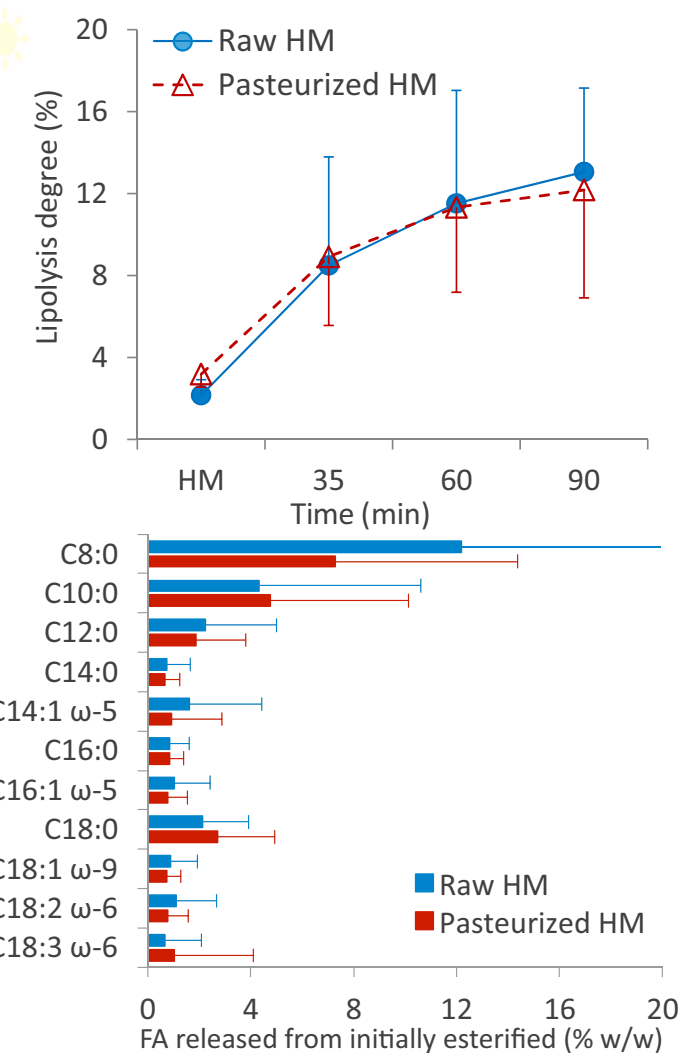

Fig. 3. Evolution of structure and lipolysis during gastric phase in vivo of raw or pasteurized human milk (de Oliveira et al., 2017).

$\mathrm{GA}=30.0 \pm 1.1 \mathrm{wk}, \mathrm{BW}=1.4 \pm 0.3 \mathrm{~kg}$, medium age $=27 \pm 12 \mathrm{wk}$ ). Trial was conducted over a 6 day period and each infant was its own control. Lipolysis, FFA, proteolysis and gastric emptying rates were characterized (Fig. 3). Despite inactivation of endogeneous lipase BSSL, lipolysis rate was not affected by pasteurization and averaged $12.6 \pm 4.7 \%$ after 90 min digestion. BSSL was responsible for pre-lipolysis occurring prior to pasteurization and was higher for PHM than in RHM (respectively $3.2 \pm 0.6 \%$ vs. $2.2 \pm 0.8 \%$ ). Emulsion destabilization was observed from 35 min onwards and characterized by smaller aggregates and higher specific surface in PHM. The gastric emptying of HM was not modified by pasteurization with half time of $\sim 30 \mathrm{~min}$ in range with the average values reported for HM in preterm infants (25-47 $\mathrm{min})$. This rapid emptying is opposed to the longest time reported for IF (72 $\mathrm{min}$ on average).

\section{Evolutions of IF in between scientific, technological and regulatory evolutions}

IF are substitute of HM which have to totally support infant growth and thus are strictly regulated by different authorities worldwide (Codex Alimentarius Commission; US Food and Drug Administration; the European commission; the European Society for Pediatric, Gastroenterology, Hepatology and Nutrition, etc.). Composition and authorized additives allowed by these authorities were already summarized by (Zou et al., 2016).
However scientific and technological advances are pushing forwards new fields of innovations in neonatal nutrition (Fig. 4). These fields are summarized on Figure 5. Details of corresponding clinical trials subcategorized in these fields of innovations are presented in Table 1. Among the emerging trends, the specific functions and metabolic fate of nanometersized lipid-protein particles termed 'lactosomes' are still unsolved (Argov-Argaman et al., 2010). These particles are devoid of a TG core, have a density equivalent to plasma highdensity lipoproteins, are enriched in immuno-modulatory proteins and are characterized by a distinct proteome and lipidome compared with MFG and high-density lipoproteins. Whether these lactosomes are similar to exosomes containing miRNA (small non-coding RNAs), which regulate several biological processes is still unknown. The cytoplasmic crescent of the MFGM (Fig. 1) entraps RNA and miRNA that would be involved in metabolic and immune regulation in the infant (Munch et al., 2013). Their putative part in lipid metabolism preprogramming remains to be elucidated.

\subsection{Fields of innovation based on recent analysis of clinical trials about infant formula (Tab. 1)}

Most clinical trials (27\%) focussed on protein composition of IF with particularly high number of trials addressing cow's milk allergy and assessing the safety of extensively hydrolyzed IF or IF based on alternate source of proteins. Other important 


\section{HISTORICAL AND REGULATORY EVOLUTIONS}

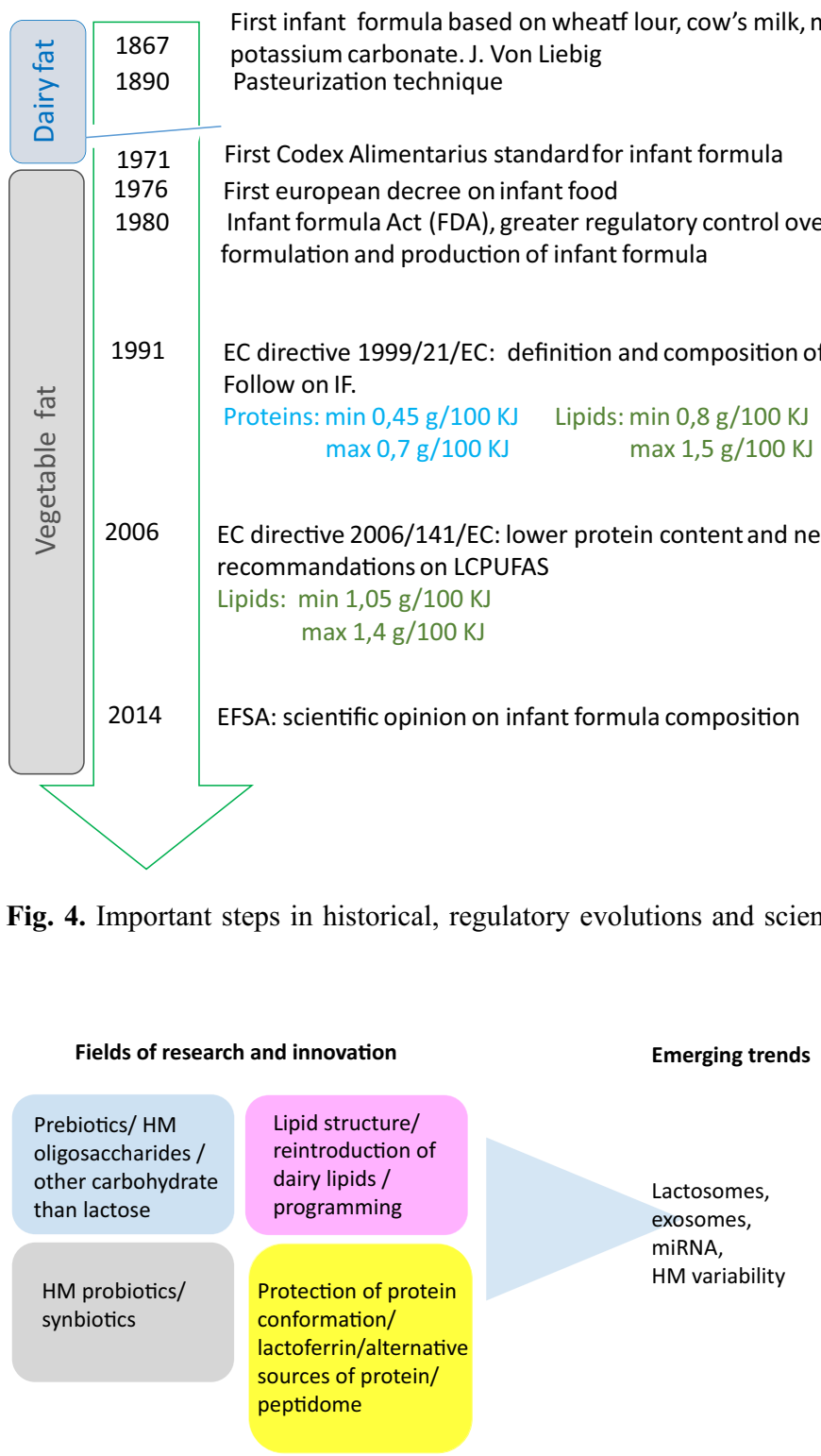

Fig. 5. Summary of fields of innovation based on recent analysis of clinical trials, WOS and patent database about infant formula.

fields of research concern prebiotics (oligosaccharides from HM notably) which promote the development of bifidogenic microbiota, probiotics possibly isolated from HM and combination of both (synbiotics) have been investigated. Clinicals trials targeting lipids in the IF represent $14 \%$ of the total trials. Topics of these trials cover supplementation with dairy lipids or fraction, structured TG, beta-palmitate, LC-PUFA supplementation, structure of lipids and programming. Combining factors to make biomimetic IF is also a trend in recent clinical trials (for instance NCT00624689 'effects of milk fat globule membrane-enriched IF with reduced energy and protein content'). Carotenoids supplementation including lutein (NCT00913406) important for brain and visual development (retina epithelium) have also been assessed (Ramirez, 2016).

\section{SCIENTIFIC EVOLUTIONS CONCERNING LIPIDS}

$\rightarrow$ 1838: determination of HM composition. J. Simons

$\rightarrow$ 1915: fat content adapted to resemble HM. Addition of cod liver oil (Gerstenberger et al., 1915)

$\rightarrow$ 1968: Importance of palmitic sn-2 position

(Tomarelli et al., 1968)

$\rightarrow$ 1996: Intervention study on structured TG Betapol $^{\circledR}$ (Carnielli et al., 1996)

\footnotetext{
$\rightarrow$ 2011: Interest of dairy fat for DHA brain accumulation (Delplanque et al., 2011) - first intervention study on MFGM extract addition in IF (Zavaleta et al., 2011)

$\rightarrow$ 2012: Structure of dairy emulsion is involved in body composition and metabolism programing (Oosting et al. 2012)
}

\subsection{Fields of innovation based on recent analysis of patents about infant formula}

More than 2000 patents about IF are registered in open database (espacenet patent). Among the most recent patents, several patents target IF supplementation with bioactive components such as oligosaccharides (US2016278421 (A1), US2016278414 (A1)), bovine colostrum component (MX2015017115 (A), modified sweet whey US2016310557, structured lipid 1,3-Dioleoyl-2-Palmitoyl glycerol WO2016 176987, etc.). Six patents registered in 2016 (US2016219911, NZ631411, US2016278413, NZ627997, US2016295895, US2016302611) corresponds to technological processes to produce new IF among which formula based on large globules. Patent WO 2010/027258 details technological ways of formulating large metastable emulsion and provide powdered formulas based on these large lipid globules emulsion. This patent addresses a true challenge as such emulsion is very metastable and that particles separation (creaming/sedimentation) during transport and storage, may result in a nutrient imbalance over the time of use. The use of micronized carbohydrates (US2016295895 (A1)) allows reducing stickiness/clumping and increasing flowability of the large droplet spray-dried IF.

\subsection{Fields of innovations corresponding to staging infant formula to mimic HM evolution during lactation}

Human milk is a variable fluid. Hence milk lipids vary with lactation stage but also diurnally and even during a single feed 
Table 1. Scientific fields of innovations reported in clinical trials dealing with IF.

\begin{tabular}{lll}
\hline Themes & $\begin{array}{l}\text { Number } \\
\text { of trials }\end{array}$ & Corresponding trial and topic \\
\hline
\end{tabular}

Prebiotics, GOS, other 22 carbohydrates than lactose

HM probiotics, synbiotics

Supplementation with dairy lipids or fraction, structured TG, betapalmitate, LC-PUFA supplementation, programming
Protein content, alternative source of prot, extensively hydrolyzed whey, reduced protein content, enriched protein faction, LF-addition
27 NCT01197365, NCT01497314, NCT01515644 (inulin), NCT00486148 (GOS), NCT00836771,
NCT01497314 (low lactose), NCT01934257 (lactose free soy or milk-based IF), NCT02363582 (prebiotic and lactoferrin containing IF on stool consistency), NCT01606683 (IF with GOS, beta-palmitate, acidified milk), NCT02796872 (GOS supplementation), NCT02586558 (prebiotic on colic and crying), NCT01715246 (2 Human Milk Oligosaccharides - HMOs), NCT02757924 (prebiotics and behaviour), NCT02746016 (IF and olisaccharides), NCT02118935 (prebiotics and early behaviour), NCT02441296 (maltodextrin or lactose added IF and metabolism), NCT00808756 (fermentable carbohydrate), NCT02703987 (fermented vs. non fermented IF and lactose tolerance), NCT01119170 (d-lactate producing probiotics), NCT00948051 (short-chain FOS enriched IF and immunity), NCT02317406 (probiotics on digestibility and immunity), NCT01788761 (probiotics on extremely low birthweight infants)

NCT01897922, NCT01625273 (synbiotics), NCT00836771, NCT02096302 (Probiotic CECT7210 on Gastrointestinal Health), NCT01017991 (probiotics for crying infants), NCT00858026 (fermented IF for weaning babies), NCT00929292 (alpha-L and probiotics' enriched for infants with colic), NCT01079208 (starter IF with synbiotics), NCT01346644 (Lactobacillus fermentum for newborn infants), NCT01755481 (added probiotics and whey protein concentrate), NCT01956682 (hypoallergenic with starch and probiotics), NCT01476397 (probiotics), NCT01886898 (synbiotics), starter with pro and prebiotics, NCT01081067 (probiotic), NCT01010113 (synbiotics), NCT02221687 (combiotic study), NCT01036243 (slightly hydrolyzed and probiotics), NCT01813175 (synbiotics), NCT01983072 (synbiotics and colonization), NCT00318695 (probiotics and atopy/immunological responses), NCT02031887 (synbiotics on stool microbiota), NCT00365469 (probiotics on atopy, immunological responses and gut microflora), NCT00711633 (new fermented milk for preterm infants), NCT00792090 (fermented formula for allergy prevention), NCT00810160 (GOS and Bifidobacterium infantis), NCT02430831 (L. reuteri supplementation and crying), NCT01279265 (L. rhamnosus GG) NCT00970398, NCT02598817 (high sn-2 IF), NCT02111837 (specific lipid faction enrichment), NCT00707837 (preterm IF with added soluble lipids), NCT02092857 (Arachidonic Acid Supplementation on the Immune Response), NCT02031003 (new fat blend or new fat blend plus fiber), NCT01603719 (milkfat and prebiotics), NCT00480948 (InFat ${ }^{\mathrm{TM}}$ on stool), NCT02144402 (B-DHA IF), NCT01058187 (long chain PUFA), NCT01140243 (long chain PUFA for preterm), NCT01373541 (InFat ${ }^{\mathrm{TM}}$ on stool), NCT01116115 (InFat ${ }^{\mathrm{TM}}$ ), NCT00874068 (InFat ${ }^{\mathrm{TM}}$ based infant formula on bone strength), NCT02503020 (AA in very preterm infant), NCT01611649 (mix dairy lipids/plant oil on w3 in red blood cell), NCT00941564 (calcium retention and different fat blends), NCT01300130 (improving DHA and ARA in preterm), NCT00753818 (DHA and ARA and development), NCT02339727 (w6/w3 and neural development), NCT01184378 (dairy lipid and soluble milk proteins), NCT01617889 (alternate fat blend), NCT00666120 (IF with DHA/ARA and +/- iron), NCT02587702 (B-palmitate and mineral metabolism), NCT02069522 (carotenoid supplementation), NCT02332967 (structured lipid with B-palmitate), NCT01908907 (DHA supplementation in preterm), NCT00379171 (fish oil supplementation), NCT00913406 (lutein fortification), NCT00872664 (IF supplemented with carotenoids on skin and serum carotenoids), NCT02033005 (breastmilk vs. IF and adipose tissue volume, development and intra-hepatocellular lipids), NCT00624689 (effects of milk fat globule membrane-enriched IF with reduced energy and protein content)

60 NCT01380886, NCT01210391, NCT01155414 (hydrolysat), NCT02469402 (reduced protein content, improved quality), NCT00938483 (extensively hydrolyzed), NCT01278446, NCT01278446 (extensively hydrolyzed), NCT02433600 (enriched protein fractions), NCT01987154 (extensively hydrolyzed casein IF for preterm), NCT01573871 (hydrolyzed IF), NCT00977964 (experimental milk protein IF), NCT02006992 (hydrolyzate IF), NCT00548106 (partially hydrolyzed whey), NCT02414243 (new aa-based IF), NCT02103205 (Bovine Lactoferrin and Low Iron Concentration IF), NCT02410057 (protein-reduced, alpha-lactalbumin enriched IF), NCT00716105 (different levels of proteins), NCT01143233 (reduced proteins, hydrolyzed with pre and probiotics), NCT02456831 (soy IF), NCT01208493 (high protein content for VLBW preterm infant), NCT00465764 (alternate protein IF), NCT01354366 (hypoallergenic IF), NCT01909661 (extensively hydrolyzed rice protein or casein), NCT02274883 (enriched protein fraction), NCT01205659 (allergy/asthma), NCT02500563 (aa-based or extensively hydrolyzed on microbiota), NCT00936637 (extensively-hydrolyzed IF), 
Table1. (continued).

\begin{tabular}{lll}
\hline Themes & $\begin{array}{l}\text { Number } \\
\text { of trials }\end{array}$ & Corresponding trial and topic \\
\hline
\end{tabular}

NCT00338689 (early programming and low protein IF), NCT00997971 (partially hydrolyzed rice protein), NCT02431377 (alpha-lactabulmin-enriched formula), NCT02010749 (protein concentration and growth up to 2 years), NCT00798382 (soy IF), NCT02719405 (resolution of cow's milk allergy : aa-based IF, extensively hydrolyzed casein IF or Lactobacillus GG containing IF), NCT02028156 (feeding intolerance), NCT00916565 (functional proteins), NCT01507935 (hydrolysed cow's milk and microbiota), NCT01569776 (aa IF), NCT01684319 (formula free of cow's milk proteins), NCT01809951 (soy-based infant formula), NCT01583673 (aa-based formula and growth), NCT01489098 (level of dietary protein on body composition), NCT00340652 (infant diets and estrogen activity), NCT02149134 (hypoallergenic IF), NCT01727115 (cow's milk intolerance), NCT02621814 (low glycation and aggregation protein), NCT02536482 (aa-based formula), NCT00664768 (hypoallergenic new IF), NCT02397876 (partially hydrolyzed whey IF), NCT02646969 (staged protein concentration over first year of life), NCT01470768 (aa-based IF), NCT01109966 (aa-based formula), NCT01156493 (hydrolyzed protein IF), NCT01637688 (aa-based IF), NCT02626143 (nutrient-rich whey protein IF), NCT02785679 (cow's milk allergy), NCT02711163 (extensively hydrolyzed IF), NCT01998074 (extensively hydrolyzed rice protein IF), NCT01584245 (aa-based IF), NCT02405923 (rice protein hydrolysate formula), NCT02351531 (thickened extensively hydrolyzed IF)

Other (1-5-
methyltetrahydrofolate, alternate source of DHA, milk hypersensitivity, iron-fortification of IF) NCT02437721, NCT02132663 (alternate source of DHA), NCT00938483, NCT01216709 (iron fortified IF), NCT00658905 (rHBSSL in IF for preterm), NCT02239588 (pure canterbury stage 1 milk powder), NCT01094080 (Modified Content of Protein and Improved Fatty Acids), NCT00000873 (high calory IF for HIV-infected infants), NCT00292812 (nucleotides supplemented IF), NCT00518414 (DHA, ARA and prebiotic IF), NCT02045784 (iodine supplements), NCT01177917 (mineral absorption), NCT00366873 (calcium absorption), NCT01413581 (rHBSSL), NCT01820494 (infant with chronic diarrhea), NCT01812629 (infant with chronic diarrhea), NCT00984230 (IF + LF + probiotics + OS), NCT01025557 (isovolumetric and isocaloric preloads of milk on food intake), NCT01042561 (vitamin D status), NCT02054091 (bovine colostrum to preterm infant), NCT00554814 (iron deficiency milk supplemented with biofer), (partially hydrolyzed and with L. reuteri), NCT01585142 (Babynes system), NCT02679183 (honey supplemented If for preterm), NCT01627015 (novel low glycemic index formula), NCT01148667 (Casein hydrolysate added with L. rhamnosus GG), NCT01166451 (iron supplemented IF)

Unknown $\quad 54 \quad$ NCT01137877, NCT01609634, NCT01681355, NCT02860026, NCT02322138, NCT02481531 (protein fraction), NCT02401217, NCT02860026, NCT02094547, NCT02490852, NCT00957892, NCT01808105, NCT02670863, NCT02073071, NCT01721850, NCT01162798, NCT01558440, NCT00655720, NCT00937014, NCT00705562, NCT02178189, NCT00820833, NCT01861600, NCT02658500, NCT02715895, NCT02405572, NCT01766011, NCT01370967, NCT00543673, NCT02456805, NCT00665938, NCT01300000, NCT02594683, NCT01721512, NCT00340665 (infant diet on estrogen activity), NCT01735123, NCT00712608, NCT00920166, NCT01466400, NCT02340143, NCT01762631, NCT01700205, NCT02710955 (anti-regurgitation formula), NCT00994747 (early flavour learning), NCT02066610 (selenium supplementation), NCT00503789, NCT00952328, NCT00740974, NCT00134771 (supplementation small for gestational age), NCT01177930, NCT00342303 (activity of essential fatty acid elongation/ desaturation during early life), NCT02425423 (anti-regurgitation), NCT01759134, NCT00506584, NCT02759809

(foremilk, hindmilk). Three stages are differentiated: colostrum (1-5 days post-delivery), transitional milk (6-15 days post-delivery) and mature milk ( $>15$ days post-delivery). The difference in the composition of main macronutrients between these stages is well documented (Jenness, 1979; Jensen, 1999; Hester et al., 2012; Guesnet et al., 2013; Michalski, 2013). Less data is available about the variation of composition and structure of lipids in mature milk as lactation time progress. This variability in HM composition suggests adaptation to the precise infant need at a given physiological stage and could be an important tool to diversify and improve IF (Harzer et al., 1983; Nommsen et al., 1991; Santoro et al., 2010; Bourlieu et al., 2015a; Lonnerdal and Hernell, 2016). Lonnerdal and Hernell (2016) even suggested recently a re-evaluation of the staging concept (Fig. 6B) to propose specific formula for 0-3 months (stage 1), 3-6 months (stage 2) and 6-12 months (stage 3 ) which could improve nutrition of formula-fed infant and make their outcomes and performance closer to HM. 


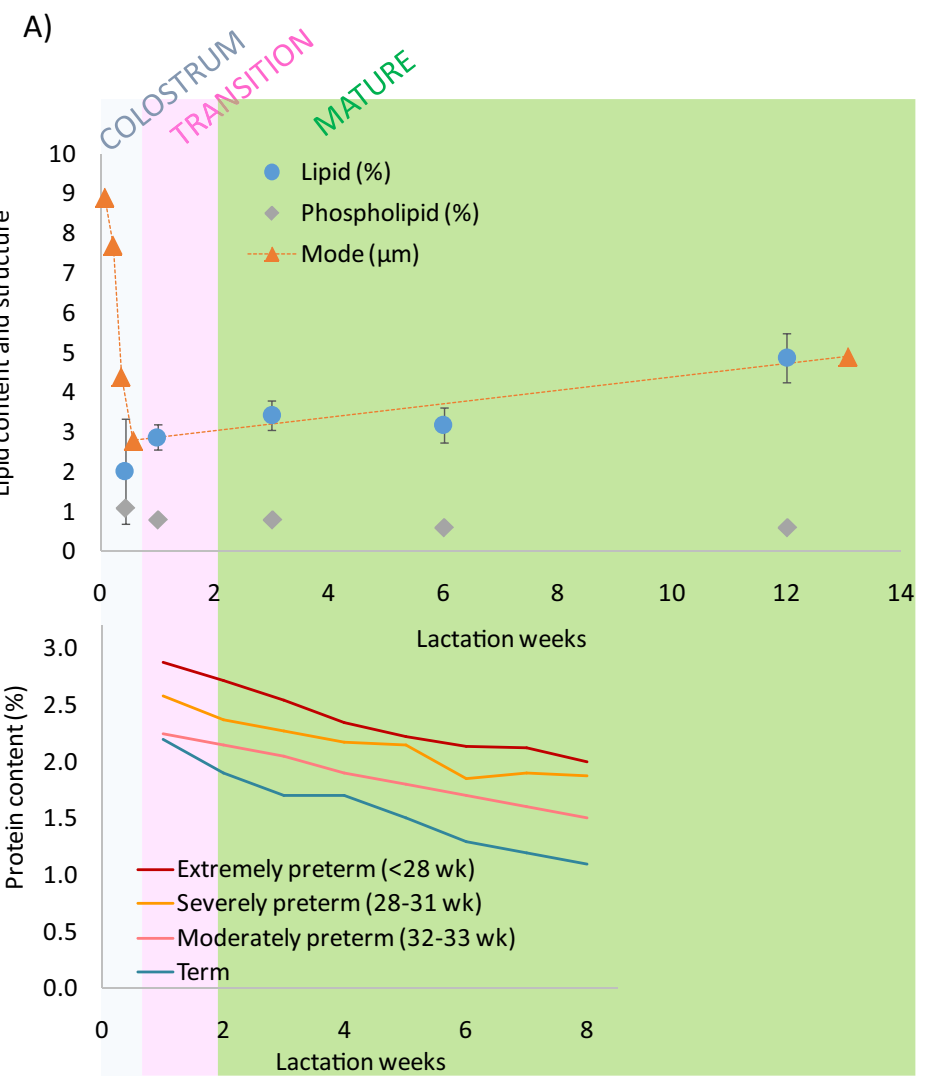

B)
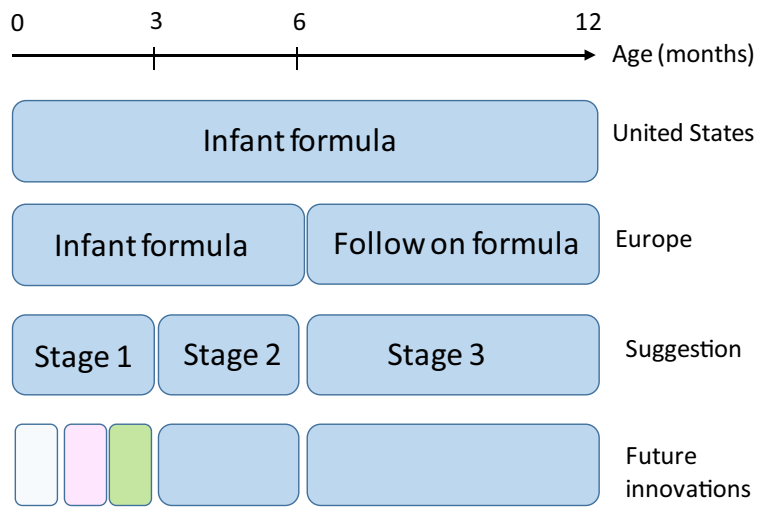

Fig. 6. Illustration of HM variability during lactation and associated concept of biomimetic staged IF. (A) Variation in lipid content and structure and in protein content of HM during lactation. (B) Concept of IF staging adapted from Lonnerdal and Hernell (2016).

Indeed when considering the total lipid content of the milk, it increases with lactation duration. This increase induces an increase in the size of the globule as the interfacial material become limiting (Fig. 6A). Typical variations reported in a study involving 120 breastfeeding Spanish mothers reported total fatty acids values of $2.02 \mathrm{~g} / 100 \mathrm{ml}$ in colostrum, $2.59 \mathrm{~g} / 100 \mathrm{ml}$ in transitional milk and $3.28 \mathrm{~g} / 100 \mathrm{ml}$ in mature milk (Jensen, 1999). In terms of quality of FA, saturated FA C8-C14 were reported to increase between the colostrum milk and the two other lactation periods (Lopez-Lopez et al., 2002). Monounsaturated FA generally decreases between colostrum and transitional or mature milks. The total polyunsaturated content of milk do not vary with the stage of lactation. However, the ratio between the two essential FA, i.e. LA/ALA evolves during lactation and can overtake the acceptable range of 5:1-15:1. The diet and physiological state of the mother also impact her milk nutritional composition. The strong impact of the diet on human milk FA profile was detailed by (ESPGAN Committee on Nutrition, 1991) and puts forward as a basis to explain the regional and seasonal fatty acid profile variation in HM. DHA in milk is also highly dependent on the DHA status of the mother but would decrease with duration of lactation. Mature HM is more influenced by maternal factors (body composition, diet and parity, etc.) than milk of early lactation (Jensen, 1999).

Regarding the structure of HM lipids emulsion and its evolution with delivery term (Simonin et al., 1984) or lactation stages, very limited data is available (Michalski et al., 2005b; Zou et al., 2012). Michalski et al. (2005b) reported an higher amount of large fat globules in early colostrum with a mode of $8.9 \mu \mathrm{m}$ at $12 \mathrm{~h}$ post-partum and which decreased rapidly to $2.8 \mu \mathrm{m}$ at $96 \mathrm{~h}$ post-partum (Fig. 6A). The MFG size then increased regularly in mature milk, from values around $5 \mu \mathrm{m}$ at 3 months lactation up to $6.5 \mu \mathrm{m}$ at 18 months.

\section{Conclusions}

The better understanding of the composition and structure of human MFG, of their behaviour in the upper digestive tract has led to development of new IF more biomimetic of HM. These formulas include bovine milk fat fractions (MFGM, TG) or are structured under the form of large droplets having diameter similar to human MFG. Proofs of evidence of the fact that the structure of lipid ingested during neonatal period programs body composition and metabolism in adulthood has been produced in animal but must be confirmed in clinical trials.

Data on the structure of HM throughout lactation and on the digestive behaviour of specific fractions of HM lipids are still needed to build a sound basis for the optimization of IF. A better understanding of fractions that escape enzymatic digestion in the upper tract and serve as substrates for microbiota will help to control microbiota shifts that exist between breast-fed and formula-fed infants. Combinations of factors (synbiotics and lipid structure) and more staging seems important levers to improve IF but their efficacy and safety still have to be assessed in clinical trials. 


\section{Abbreviations}

$\begin{array}{ll}\text { ALA } & \text { alpha-linolenic acid } \\ \text { LA } & \text { linoleic acid } \\ \text { ARA } & \text { arachidonic acid } \\ \text { DHA } & \text { docosahexaenoic acid } \\ \text { FA } & \text { fatty acid } \\ \text { FFA } & \text { free fatty acid } \\ \text { HM } & \text { human milk } \\ \text { IF } & \text { infant formula } \\ \text { LCPUFA } & \text { long chain polyunsaturated fatty acids } \\ \text { MFG } & \text { milk fat globules } \\ \text { MFGM } & \text { milk fat globule membrane } \\ \text { MPL } & \text { milk polar lipids } \\ \text { TG } & \text { triacylglycerides } \\ \text { sn } & \text { stereo-numbering }\end{array}$

\section{References}

Agostoni C, Braegger C, Decsi T, et al. 2009. Breast-feeding: a commentary by the ESPGHAN Committee on Nutrition. $J$ Pediatr Gastroenterol Nutr 49 (1): 112-125.

Ailhaud G, Massiera F, Weill P, Legrand P, Alessandri JM, Guesnet P. 2006. Temporal changes in dietary fats: role of $n-6$ polyunsaturated fatty acids in excessive adipose tissue development and relationship to obesity. Progr Lipid Res 45 (3): 203-236.

Amara S, Patin A, Giuffrida F, et al. 2014. In vitro digestion of citric acid esters of mono- and diglycerides (CITREM) and CITREMcontaining infant formula/emulsions. Food Funct 5 (7): 1409-1421.

Argov-Argaman N, Smilowitz JT, Bricarello DA, et al. 2010. Lactosomes: structural and compositional classification of unique nanometer-sized protein lipid particles of human milk. J Agric Food Chem 58 (21): 11234-11242.

Armand M, Hamosh M, Mehta NR, et al. 1996. Effect of human milk or formula on gastric function and fat digestion in the premature infant. Pediatr Res 40 (3): 429-437.

Armand M, Pasquier B, André M, et al. 1999. Digestion and absorption of 2 fat emulsions with different droplet sizes in the human digestive tract. Am J Clin Nutr 70 (6): 1096-1106.

Arrieta MC, Stiemsma LT, Amenyogbe N, Brown EM, Finlay B. 2014. The intestinal microbiome in early life: health and disease. Front Immunol 5: 427.

Baars A, Oosting A, Engels E, et al. 2016. Milk fat globule membrane coating of large lipid droplets in the diet of young mice prevents body fat accumulation in adulthood. Br J Nutr 115 (11): 1930-1937.

Bernback S, Blackberg L, Hernell O. 1990. The complete digestion of human milk triacylglycerol in vitro requires gastric lipase, pancreatic colipase-dependent lipase and bile salt stimulated lipase. J Clin Investigation 85: 1221-1225.

Billeaud C, Puccio G, Saliba E, et al. 2014. Safety and tolerance evaluation of milk fat globule membrane-enriched infant formulas: a randomized controlled multicenter non-inferiority trial in healthy term infants. Clin Med Insights: Pediatr 8: 51-60.

Bourlieu C, Bouhallab S, Lopez C. 2009. Biocatalyzed modifications of milk lipids: applications and potentialities. Trends Food Sci Techn 20 (10): 458-469.

Bourlieu C, Michalski MC. 2015. Structure-function relationship of the milk fat globule. Curr Opin Clin Nutr Metab Care 18 (2): $118-127$.
Bourlieu C, Ménard O, Bouzerzour K, et al. 2014. Specificity of infant digestive conditions: some clues for developing relevant in vitro models. Crit Rev Food Sci Nutr 54 (11): 1427-1457.

Bourlieu C, Bouzerzour K, Ferret-Bernard S, et al. 2015a. Infant formula interface and fat source impact on neonatal digestion and gut microbiota. Eur J Lipid Sci Technol 117 (10): 1500-1512.

Bourlieu C, Mnard O, De La Chevasnerie A, et al. 2015b. The structure of infant formulas impacts their lipolysis, proteolysis and disintegration during in vitro gastric digestion. Food Chem 182: 224-235.

Bourlieu C, Paboeuf G, Chever S, et al. 2016. Adsorption of gastric lipase onto multicomponent model lipid monolayers with phase separation. Colloids Surf B: Biointerfaces 143: 97-106.

Bouzerzour K, Morgan F, Cuinet I, et al. 2012. In vivo digestion of infant formula in piglets: protein digestion kinetics and release of bioactive peptides. British J Nutr 108 (12): 2105-2114.

Chatterton DEW, Rasmussen JT, Heegaard CW, Sorensen ES, Petersen TE. 2004. In vitro digestion of novel milk protein ingredients for use in infant formulas: research on biological functions. Trends Food Sci Technol 15: 373-383.

Chu BS, Gunning AP, Rich GT, et al. 2010. Adsorption of bile salts and pancreatic colipase and lipase onto digalactosyldiacylglycerol and dipalmitoylphosphatidylcholine monolayers. Langmuir 26 (12): 9782-9793.

Committee on the evaluation of the addition of ingredients new to infant Formula. 2004. Comparing infant formula with human milk. In: Infant formula: evaluating the safety of new ingredients. Washington D.C.: The National Academy Press, pp. 41-54.

Cone T. 1981. History of infant and child feeding: from the earliest years through the development of scientific concepts. In: Bond JT, ed. Infant and child feeding. New-York: Academic Press, pp. 4-34.

Conway V, Gauthier SF, Pouliot Y. 2014. Buttermilk: much more than a source of milk phospholipids. Anim Front 4 (2): 44-51.

de Oliveira SC, Deglaire A, Ménard O, et al. 2015. Pasteurization impacts the proteolysis, lipolysis and disintegration of human milk under in vitro dynamic term newborn digestion. Food Res Int 88 (B): 263-275.

de Oliveira SC, Bourlieu C, Ménard O, et al. 2016. Impact of pasteurization of human milk on preterm newborn in vitro digestion: gastrointestinal disintegration, lipolysis and proteolysis. Food Chem 211: 171-179.

de Oliveira SC, Bellanger A, Ménard O, et al. 2017. Impact of human milk pasteurization on gastric digestion in preterm infants: a randomized controlled trial. Am J Clin Nutr 105 (2): 379-390.

Delplanque B, Du Q, Leruyet P, et al. 2011. Brain docosahexaenoic acid (DHA) levels of young rats are related to alpha-linolenic acid (ALA) levels and fat matrix of the diet: impact of dairy fat. $O C L$ 18 (6): 293-296.

Delplanque B, Du Q, Agnani G, Le Ruyet P, Martin JC. 2013. A dairy fat matrix providing alpha-linolenic acid (ALA) is better than a vegetable fat mixture to increase brain DHA accretion in young rats. Prostaglandins, Leukot Essent Fatty Acids (PLEFA) 88 (1): $115-120$.

Delplanque B, Gibson R, Koletzko B, Lapillonne A, Strandvik B. 2015. Lipid quality in infant nutrition: current knowledge and future opportunities. J Ped Gastroenterol Nutr 61 (1): 8-17.

Dupont D, Mandalari G, Mollé D, et al. 2010. Food processing increases casein resistance to simulated infant digestion. Mol Nutr Food Res 54 (11): 1677-1689. DOI: 10.1002/mnfr.200900582.

El-Loly M. 2011. Composition, properties and nutritional aspects of milk fat globule membrane - a review. Pol J Food Nutr Sci 61 (1): 7-32. 
ESPGAN Committee on Nutrition. 1991. Comments on the content and composition of lipids in infant formulas. Acta Paediatr Scand 80: 887-896.

Fondaco D, AlHasawi F, Lan Y, Ben-Elazar S, Connolly K, Rogers M. 2015. Biophysical aspects of lipid digestion in human breast milk and similac((TM)) infant formulas. Food Biophys 10 (3): 282-291.

Fujisawa Y, Yamaguchi R, Nagata E, et al. 2013. The lipid fraction of human milk initiates adipocyte differentiation in 3T3-L1 cells. Early Hum Dev 89 (9): 713-719.

Gaillard D, Negrel R, Lagarde M, Ailhaud G. 1989. Requirement and role of arachidonic acid in the differentiation of pre-adipose cells. Biochem J 257: 389-397.

Gallier S, Gragson D, Jimenez-Flores R, Everett D. 2010. Using confocal laser scanning microscopy to probe the milk fat globule membrane and associated proteins. J Agric Food Chem 58 (7): 4250-4257.

Gallier S, Ye A, Singh H. 2012. Structural changes of bovine milk fat globules during in vitro digestion. J Dairy Sci 95 (7): 3580-3592.

Gallier S, Cui J, Olson TD, et al. 2013a. In vivo digestion of bovine milk fat globules: effect of processing and interfacial structural changes. I. Gastric digestion. Food Chem 141 (3): 3273-3281.

Gallier S, Zhu XQ, Rutherfurd SM, Ye A, Moughan PJ, Singh H. 2013b. In vivo digestion of bovine milk fat globules: effect of processing and interfacial structural changes. II. Upper digestive tract digestion. Food Chem 141 (3): 3215-3223.

Gallier S, Vocking K, Post JA, et al. 2015. A novel infant milk formula concept: Mimicking the human milk fat globule structure. Colloids Surf B: Biointerfaces 136: 329-339.

Garcia C, Antona C, Robert B, Lopez C, Armand M. 2014. The size and interfacial composition of milk fat globules are key factors controlling triglycerides bioavailability in simulated human gastro-duodenal digestion. Food Hydrocolloids 35: 494-504.

Gassi JY, Blot M, Beaucher E, et al. 2016. Preparation and characterisation of a milk polar lipids enriched ingredient from fresh industrial liquid butter serum: combination of physicochemical modifications and technological treatments. Int Dairy $J$ 52: $26-34$.

Golding M, Wooster TJ. 2010. The influence of emulsion structure and stability on lipid digestion. Curr Opin Colloid Interface Sci 15 (1-2): 90-101.

Guesnet P, Ailhaud G, Delplanque B, Alessandri JM. 2013. Place des lipides dans l'alimentation du nourrisson. Cahiers de Nutrition et de Diététique 48 (4): 175-183.

Gurnida DA, Rowan AM, Idjradinata P, Muchtadi D, Sekarwana N. 2012. Association of complex lipids containing gangliosides with cognitive development of 6-month-old infants. Early Hum Dev 88 (8): 595-601.

Harzer G, Haug M, Dieterich I, Gentner PR. 1983. Changing patterns of human milk lipids in the course of the lactation and during the day. Am J Clin Nutr 37 (4): 612-621.

Hernell O, Timby N, Domellöf M, Lönnerdal B. 2016. Clinical benefits of milk fat globule membranes for infants and children. J Pediatr 173 (Suppl.): S60- S65.

Hester SN, Hustead DS, Mackey AD, Singhal A, Marriage BJ. 2012. Is the macronutrient intake of formula-fed infants greater than breast-fed infants in early infancy? J Nutr Metab 2012: $1-13$.

Hirabayashi Y, Furuya S. 2008. Roles of 1-serine and sphingolipid synthesis in brain development and neuronal survival. Progr Lipid Res 47 (3): 188-203.

Innis SM. 2011. Dietary triacylglycerol structure and its role in infant nutrition. Adv Nutr: Int Rev J 2 (3): 275-283.
Innis SM, Dai C, Wu X, Buchan AMJ, Jacobson K. 2010. Perinatal lipid nutrition alters early intestinal development and programs the response to experimental colitis in young adult rats. $\mathrm{Am} \mathrm{J}$ Physiol - Gastrointest Liver Physiol 299 (6): G1376- G1385.

Jenness R. 1979. The composition of human milk. Semin Perinatol 3 (3): 225-239.

Jensen RG, Hagerty MM, McMahon KE. 1978. Lipids of human milk and infant formulas: a review. Am J Clin Nutr 31 (6): 990-1016.

Jensen RG. 1999. Lipids in human milk. Lipids 34 (12): 1243-1271.

Kullenberg D, Taylor LA, Schneider M, Massing U. 2012. Health effects of dietary phospholipids. Lipids Health Dis 11 (1): 1-16.

Kurvinen J, Sjövall O, Kallio H. 2002. Molecular weight distribution and regioisomeric structure of triacylglycerols in some common human milk substitutes. J Am Oil Chem Soc 79 (1): 13.

Lapillonne A. 2007. DHA et développement du cerveau de l'enfant. OCL 14 (1): 25-27.

Le Huërou-Luron I, Blat S, Boudry G. 2010. Breast- v formula feeding: impacts on the digestive tract and immediate and longterm health effects. Nutr Res Rev 23 (1): 23-36.

Le Huërou-Luron I, Bouzerzour K, Ferret-Bernard S, et al. 2014. Addition of milk fat in infant formula impacts neonatal gut microbiota. In: The 11 Biennial ISSFAL Congress 2014. The 11 Biennial ISSFAL Congress 2014, Stockholm (Suède).

Le Huërou-Luron I, Bouzerzour K, Bernard-Ferret S, et al. 2016. A mixture of milk and vegetable lipids in infant formula improves gut digestion, physiology and microbiota in neonatal piglets. Eur J Nutr, DOI:10.1007/s00394-016-1329-3P.

Lonnerdal B. 2014. Infant formula and infant nutrition: bioactive proteins of human milk and implications for composition of infant formulas. Am J Clin Nutr 99 (3): 712S-717S.

Lonnerdal B, Hernell O. 2016. An opinion on staging of infant formula: a developmental perspective on infant feeding. J Pediatr Gastroenterol Nutr 62 (1): 9-21.

Lopez C, Ménard O. 2011. Human milk fat globules: polar lipid composition and in situ structural investigations revealing the heterogeneous distribution of proteins and the lateral segregation of sphingomyelin in the biological membrane. Colloids Surf B: Biointerfaces 83 (1): 29-41.

Lopez C, Cauty C, Guyomarc'h F. 2015. Organization of lipids in milks, infant milk formulas and various dairy products: role of technological processes and potential impacts. Dairy Sci Technol 95 (6): 863-893.

Lopez-Lopez A, Lopez-Sabater MC, Campoy-Folgosa C, RiveroUrgell M, Castellote-Bargallo AI. 2002. Fatty acid and $s n-2$ fatty acid composition in human milk from Granada (Spain) and in infant formulas. Eur J Clin Nutr 56: 1242-1254.

Lueamsaisuk C, Lentle R, MacGibbon A, Matia-Merino L, Golding M. 2014. Factors influencing the dynamics of emulsion structure during neonatal gastric digestion in an in vitro model. Food Hydrocolloids 36: 162-172.

Macierzanka A, Sancho AI, Mills ENC, Rigby NM, Mackie AR. 2009. Emulsification alters simulated gastrointestinal proteolysis of [small beta]-casein and [small beta]-lactoglobulin. Soft Matter 5 (3): 538-550.

Martin JC, Bougnoux P, Antoine JM, Lanson M, Couet C. 1993. Triacylglycerol structure of human colostrum and mature milk. Lipids 28 (7): 637-643.

Maslowski KM, Mackay CR. 2011. Diet, gut microbiota and immune responses. Nat Immunol 12: 5-9.

Massiera F, Saint-Marc P, Seydoux J, et al. 2003. Arachidonic acid and prostacyclin signaling promote adipose tissue development: a human health concern? J Lipid Res 44: 271-279. 
Michalski M-C. 2013. Lipids and milk fat globules properties in human milk. In: Zibadi S, Watson RR, Prudy VR, eds. Handbook of dietary and nutritional aspects of breast milk. Wagueningen: Wagueningen Academic Pusblishers, pp. 310-329.

Michalski M-C, Briard V, Desage M, Geloen A. 2005a. The dispersion state of milk fat influences triglyceride metabolism in the rat - a $13 \mathrm{CO}_{2}$ breath test study. Eur J Nutr 44 (7): 436-444.

Michalski M-C, Briard-Bion V, Michel F, Tasson F, Poulain P. 2005b. Size distribution of fat globules in human colostrum, breast milk and infant formula. J Dairy Sci 88: 1927-1940.

Michalski MC, Soares AF, Lopez C, Leconte N, Briard V, Geloen A. 2006. The supramolecular structure of milk fat influences plasma triacylglycerols and fatty acid profile in the rat. Eur J Nutr 45 (4): 205-224.

Michalski MC, Calzada C, Makino A, Michaud S, Guichardant M. 2008. Oxidation products of polyunsaturated fatty acids in infant formulas compared to human milk. A preliminary study. Mol Nutr Food Res 52 (12): 1478-1485.

Morin P, Pouliot Y, Jimnez-Flores R. 2006. A comparative study of the fractionation of regular buttermilk and whey buttermilk by microfiltration. J Food Eng 77 (3): 521-528.

Morin P, Britten M, Jimenez-Flores R, Pouliot Y. 2007a. Microfiltration of buttermilk and washed cream buttermilk for concentration of milk fat globule membrane components. J Dairy Sci 90 (5): 2132-2140.

Morin P, Jimenez-Flores R, Pouliot Y. 2007b. Effect of processing on the composition and microstructure of buttermilk and its milk fat globule membranes. Int Dairy J 17 (10): 1179-1187.

Munch EM, Harris RA, Mohammad M, et al. 2013. Transcriptome profiling of microRNA by next-gen deep sequencing reveals known and novel miRNA species in the lipid fraction of human breast milk. PLoS ONE 8 (2): e50564.

Nilsson A, Duan R-D. 2006. Absorption and lipoprotein transport of sphingomyelin. J Lipid Res 47: 154-171.

Nommsen LA, Lovelady CA, Heinig MJ, Lonnerdal B, Dewey KG. 1991. Determinants of energy, protein, lipid, and lactose concentrations in human milk during the first 12 mo of lactation: the DARLING study. Am J Clin Nutr 53 (2): 457-465.

Nommsen-Rivers LA, Dewey KG. 2009. Growth of breastfed infants. Breastfeed Med 4 (s1): S-45.

Oosting A, Kegler D, Boehm G, Jansen HT, van de Heijning BJM, van der Beek EM. 2010. N-3 long-chain polyunsaturated fatty acids prevent excessive fat deposition in adulthood in a mouse model of postnatal nutritional programming. Pediatr Res 68 (6): 494-499.

Oosting A, Engels E, Kegler D, Abrahamse M, Teller I, Van Der Beek E. 2011. A more breast milk-like infant formula reduces excessive body fat accumulation in adult mice. Pediatr Res 70 (S5): 837.

Oosting A, Kegler D, Wopereis HJ, et al. 2012. Size and phospholipid coating of lipid droplets in the diet of young mice modify body fat accumulation in adulthood. Pediatr Res 72 (4): 362-369.

Oosting A, van Vlies N, Kegler D, et al. 2014. Effect of dietary lipid structure in early postnatal life on mouse adipose tissue development and function in adulthood. Br J Nutr 111 (2): 215-226.

Owen CG, Whincup PH, Odoki K, Gilg JA, Cook DG. 2002. Infant feeding and blood cholesterol: a study in adolescents and a systematic review. Pediatrics 110 (3): 597-608. http://pediatrics. aappublications.org/content/110/3/597.abstract

Poppitt SD, McGregor RA, Wiessing KR, et al. 2014. Bovine complex milk lipid containing gangliosides for prevention of rotavirus infection and diarrhoea in northern Indian infants. $J$ Pediatr Gastroenterol Nutr 59 (2): 167-171.
Raiten DJ, Steiber AL, Carlson SE, et al. 2016. Working group reports: evaluation of the evidence to support practice guidelines for nutritional care of preterm infant. Pre-B project. Am J Clin Nutr 103 (2): 648S-678S.

Ramirez M. 2016. Why lutein is important for the eye and the brain. OCL 23 (1): 1-6.

Reiser R, O’Brien BC, Henderson GR, Moore RW. 1979. Studies on a possible function for cholesterol in milk. Nutr Rep Int 19: 835-849.

Roman C, Carrière F, Villeneuve P, et al. 2007. Quantitative and qualitative study of gastric lipolysis in premature infants: do MCT-enriched infant formulas improve fat digestion? Pediatr Res 61 (1): 83-88.

Santoro W Jr, Martinez FE, Ricco RG, Jorge SM. 2010. Colostrum ingested during the first day of life by exclusively breastfed healthy newborn infants. J Pediatr 156 (1): 29-32.

Shani-Levi C, Alvito PC, Andrés A, et al. 2016. Extending in-vitro digestion models to specific human populations: perspectives, practical tools and bio-relevant information. Trends Food Sci Technol 60: 52-63.

Simonin C, Rüegg M, Sidiropoulos D. 1984. Comparison of the fat content and fat globule size distribution of breast milk from mothers delivering term and preterm. Am J Clin Nutr 40 (4): 820 826.

Singh H, Ye H, Horne D. 2009. Structuring food emulsions in the gastrointestinal tract to modify lipid digestion. Progr Lipid Res 48 (2): 92-100.

Sprong RC, Hulstein MF, Van Der Meer R. 2001. Bactericidal activities of milk lipids. Antimicrob Agents Chemother (April): 1298-1301.

Straarup EM, Lauritzen L, Faerk J, Hoy D, Michaelsen KF. 2006. The stereospecific triacylglycerol structures and fatty acid profiles of human milk and infant formulas. J Pediatr Gastroenterol Nutr 42 (3): 293-299.

Sugar IP, Mizuno NK, Momsen MM, Brockman HL. 2001. Lipid lateral organization in fluid interfaces controls the rate of colipase association. Biophys $J 81$ (6): 3387-3397.

Sugar IP, Mizuno NK, Momsen MM, Momsen WE, Brockman HL. 2003. Regulation of lipases by lipid-lipid interactions: implications for lipid-mediated signaling in cells. Chem Phys Lipids 122 (1-2): 53-64.

Timby N, Domellof E, Hernell O, Lonnerdal B, Domellof M. 2014a. Neurodevelopment, nutrition, and growth until 12 mo of age in infants fed a low-energy, low-protein formula supplemented with bovine milk fat globule membranes: a randomized controlled trial. Am J Clin Nutr 99 (4): 860-868.

Timby N, Lonnerdal B, Hernell O, Domellof M. 2014b. Cardiovascular risk markers until 12 mo of age in infants fed a formula supplemented with bovine milk fat globule membranes. Pediatr Res 76 (4): 394-400.

Timby N, Hernell O, Vaarala O, Melin M, Lonnerdal B, Domellof M. 2015. Infections in infants fed formula supplemented with bovine milk fat globule membranes. J Pediatr Gastroenterol Nutr 60 (3): 384-389.

Tomarelli RM, Meyer BJ, Weaber JR, Bernhart FW. 1968. Effect of positional distribution on the absorption of the fatty acids of human milk and infant formulas. J Nutr 95 (4): 583-590.

Veereman-Wauters G, Staelens S, Rombaut R, et al. 2012. Milk fat globule membrane (INPULSE) enriched formula milk decreases febrile episodes and may improve behavioral regulation in young children. Nutrition 28: 749-752.

Victora CG, Bahl R, Barros AJD, et al. 2016. Breastfeeding in the 21st century: epidemiology, mechanisms, and lifelong effect. Lancet 387 (10017): 475-490. 
Vors C, Pineau G, Gabert L, et al. 2013. Modulating absorption and postprandial handling of dietary fatty acids by structuring fat in the meal: a randomized crossover clinical trial. Am J Clin Nutr 97 (1): 23-36.

Yehuda S, Rabinovitz S, Mostofsky D. 2005. Essential fatty acids and the brain: from infancy to aging. Neurobiol Aging 26: 98-102.

Zavaleta N, Kvistgaard AS, Graverholt G, et al. 2011. Efficacy of an MFGM-enriched complementary food in diarrhea, anemia, and micronutrient status in infants. $J$ Pediatr Gastroenterol Nutr 53 (5): 561-568.
Zhang Q, Cundiff JK, Maria SD, et al. 2014. Differential digestion of human milk proteins in a simulated stomach model. J Proteome Res 13 (2): 1055-1064.

Zou L, Pande G, Akoh CC. 2016. Infant formula fat analogs and human milk fat: new focus on infant developmental needs. Annu Rev Food Sci Technol 7 (1): 139-165.

Zou XQ, Guo Z, Huang JH, et al. 2012. Human milk fat globules from different stages of lactation: a lipid composition analysis and microstructure characterization. J Agric Food Chem 60 (29): 7158-7167.

Cite this article as: Bourlieu C, Deglaire A, de Oliveira SC, Ménard O, Le Gouar Y, Carrière F, Dupont D. 2017. Towards infant formula biomimetic of human milk structure and digestive behaviour. OCL 24(2): D206. 